\title{
ANALYTICAL HIERARCHY PROCESS METHOD AND DATA ENVELOPMENT ANALYSIS APPLICATION IN TERRAIN VEHICLE SELECTION
}

\author{
Slobodan STARČEVIĆ ${ }^{*}$, Nebojša BOJOVIĆ², Raimundas JUNEVIČIUS3", Viktor SKRICKIJ ${ }^{4}$ \\ ${ }^{1}$ Ministry of Defence Republic of Serbia, Belgrade, Republic of Serbia \\ ${ }^{2}$ Faculty of Transport and traffic Engineering, University of Belgrade, Belgrade, Republic of Serbia \\ ${ }^{3}$ Dept of Mobile Machinery and Railway Transport, Vilnius Gediminas Technical University, Vilnius, Lithuania \\ ${ }^{4}$ Transport and Logistics Competence Centre, Vilnius Gediminas Technical University, Vilnius, Lithuania
}

Received 14 March 2019; revised 22 April 2019; accepted 24 May 2019

\begin{abstract}
Selection of a terrain vehicle for performing different tasks is an important factor, which influences the mobility of a user through the quality of conducting transport activities. This paper is dealing with the problem of the terrain vehicle selection for the equipping of military units which, are to be engaged in multinational operations, using the Analytical Hierarchy Process (AHP) method and Data Envelopment Analysis (DEA). Determination of the relative importance of criteria, which are used for evaluation of potential alternatives is conducted through AHP method. The results proposed by the AHP method are used as multiple outputs of the defined DEA model for the selection of the terrain vehicle. Based on the DEA model the efficiencies of alternatives are defined and also the final ranking of alternatives is determined. Besides the hybrid model AHP-DEA, which is the integral part of a basic multicriteria model in this paper the possible applications of Best Worst Method (BWM) and FUll COnsistency Model (FUCOM) are presented through validation of models. The validation is conducted through statistical data obtained by application of different multicriteria techniques, using Spearman's Correlation Coefficient (SCC).
\end{abstract}

Keywords: terrain vehicle, selection, alternative, multicriteria selection, AHP, DEA, BWM, FUCOM.

\author{
Abbrivations \\ ABS - Anti-lock Braking System; \\ AHP - Analytical Hierarchy Process; \\ BMW - Best Worst Method; \\ DEA - Data Envelopment Analysis; \\ DEMATEL - DEcision MAking Trial and Evaluation La- \\ boratory; \\ DMU - Decision-Making Unit; \\ FUCOM - FUll COnsistency Model; \\ GPS - Global Positioning System; \\ SCC - Spearman's Correlation Coefficient; \\ TOPSIS - Technique for Order of Preference by Simi- \\ larity to Ideal Solution.
}

\section{Introduction}

One of the most important tasks of the armed forces is the active contribution to the regional and global peace and security, which can be done through participation in the multinational operations. The armed forces can be engaged in the wide range of the multinational operations, which therefore demands work on the unit's capabilities to fully respond to the defined missions. The unit's ability to respond on time, qualitatively and securely, to accomplish the given tasks within the multinational operations, among all, depends on the efficiency of the transport logistic system. Managing such a system of transport logistics directly depends on the level of the unit equipment with an adequate transportation means, that is, the usage of the modern transport means in multinational operations became necessary.

Decision-making about the selection of an adequate transportation means for the military units to be engaged in multinational operations and their equipping is a very difficult task and depends on many factors: available finances, defined tasks and mission characteristics, offered types of vehicles characteristics etc. Therefore in this pa-

\footnotetext{
*Corresponding author. E-mail: slobodan.starcevic@mod.gov.rs

\#Deputy Editor-in-Chief of the TRANSPORT - the manuscript was handled by one of the Associate Editors, who made all decisions related to the manuscript (including the choice of referees and the ultimate decision on the revision and publishing). 
per, there is a scientific method approach applied to the selection of the terrain vehicles for the needs of the armed forces units engaged in the multinational operations.

Regarding efficiency of all multinational operations it is impossible not to notice its significant dependance on adequate selection of transport means for mission accomplishing, since this very process represents one of the most important factors directly influencing risk reduction, also reduction of time necesary for task accomplishing. By the adequate evaluation and the right selection of transport vehicles conditions are provided for efficient accomplishment of tasks set to multinational units. Considering the abovesaid the process of selection of an optimal transport means in multionational operations is of utmost importance for safe and succesful work of multinational units. By determining the key influences to the efficiency of transport means during task accomplishment, users are provided with the optimisation of actions and time reduction necessary for their accomplishment. In this research a multicritiria AHP-DEA model has been introduced for the purpose of evaluation and selection of an optimal terrain vehicle for units taking part in multinational operations. A hybrid AHP-DEA model is implemented in two phases. The first phase of the model includes evaluation of alternatives through hierarchy of critirea by AHP model implementation. In the next phase DEA model is implemented. The entry values in DEA model represent weighting factor of the first hierarchy level of AHP model. By implementing DEA model one can obtain the efficiencies of DMU (alternatives), that is the final ranking list of alternatives by DEA model is obtained.

Through research and development of models in this paper several objectives are presented. The first objective is related to improvement and enhancement of methodology for the selection of an optimal transport means in the field of multicrtieria decision-making through development and introduction of a new AHP-DEA approach. The second objective of this work is bridging the gap existing currently in methodology of evaluation and selection of an adequate transport means in multinational operations and army in general. The third objective of this paper is a possibility of improvement of efficiency and risk reduction during perfomance of multinational operations unit tasks through model defining for an adequate transport means selection. And the fourth objective of this paper is popularisation and affirmation of the idea of multicretiria decision-making in reaching complex decisions through presentation of a hybrid AHP-DEA model.

Authors of this paper opted for implementation of the hybrid AHP-DEA model for following advantages:

1) the implementation of AHP in DEA model enables a successful simulation of decision-making process starting from the objective definition, criteria, alternative pairs and result obtaining, that is determining priorities of all alternatives related to the set task;

2) by applying AHP-DEA model the real decisionmaking process is decomposed through dissolving of a problem in the hierarchy of elements of a process. Through the hierarchy of a decision-making process easier control of evaluation consistency is enabled, taking into consideration the whole problem and functional interactions of criteria and alternatives;

3) through AHP-DEA model qualitative and quantitative factors of decision-making are integrated, since real problems most often present combination of psychological and physical activities, that is qualitative and quantitative elements;

4) by using AHP-DEA the inconsistency of decision makers is successfully identified and pointed at, by following inconsistency in the evaluation of the whole process, calculating index and coefficient of consistency;

5) redundancy of pair comparison leads to the less sensitivity of AHP-DEA model to the evaluation errors;

6) by applying AHP-DEA model in group decisionmaking, communication among group members is significantly improved. In case of a dicussion, the group has to agree about every joint evaluation put into the matrix. In this way discussion structuring and consensus reaching are improved;

7) results of decisions reached by using AHP-DEA do not include only ranking alternatives, but also information on weighting factors of alternative criteria and efficiency.

This paper comprises six sections, where the first one is related to the importance of an adequate transport means selection. In the Section 1 related to the literature review, there is an overview of research with similar topics where methods of multiple critiria have been applied. In the Section 2 there is a short summary of the used models and the algorithm of a hybrid AHP-DEA model. In the Section 3 a case study is presented with evaluation of transport means selection by using AHP-DEA model. The Section 4 consists of sensitivity analysis that includes stability check of results through the change of weight factors criteria in AHP and DEA models and validation of obtained results through comparing with FUCOM and BWM. In the last section key contributions to the model development and conducted research have been presented, as well as suggestions for future research.

\section{Literature review}

AHP represents one of the most known methods for the multicriteria decision-making, which is used in the complex problem solving. APH method was developed in the 1970's by Thomas L. Saaty (Saaty 1980). The power of this method is in the possibility to include non-material factors as relevant factors in the process of decision-making, creating the conditions for its application in the different fields of management, marketing, engineering, education and economy. The wide application of AHP method in many fields of life is due to its simplicity and great flexibility. 
Beside its application in the field of finances (Steuer, $\mathrm{Na}$ 2003) the AHP method is used in the fields such as: education, engineering, industry, management, production, politics and sport (Vaidya, Kumar 2006), as well as in vehicle selection problem solving (Aghdaie, Yousefi 2011; Byun 2001; Apak et al. 2012; Stefanović-Marinović et al. 2017).

AHP method represents a very important engineering tool for making rational decisions where multiple criteria are present. That is the case where AHP was used for reaching a strategic decision in transport system, that is reconfiguration of railway infrastructure in Triesta port (Giacomini et al. 2016). In research by Ignaccolo et al. (2017) this method was used in determining the importance of crtieria while evaluating different transit alternatives in transport in Katania. Raymundo and Reis (2017) used AHP method for identifying and evaluating of shortcomings in passenger transport system, while Olivková (2017) used AHP method for alternative selection in electronic toll collection. Popović et al. (2018) used combination of AHP and DEMATEL methods in the field of risk, that is during integration of logistics information. Integration of AHP and DEMATEL method is not rare, since through that integration, lack of solid hierarchical structure in AHP method is eliminitaed (Chatterjee et al. 2017; Pamučar et al. 2018b; Mukhametzyanov, Pamučar 2018). Therefore, Adalı and Işı (2016) conducted integration of DEMATEL, AHP and DEA methods in a hybrid model for making decisions on 3PL logictic provider selection.

AHP method characteristics surely make its application possible in the multicriteria problem solving and decision-making in military systems. Rhonda Aull-Hyde and Davis (2012) have shown in their work the possibilities and advantages of the AHP method application in the process of decision-making in the military system of the Ministry of Defence of the US, while Crary et al. (2002) have described the application of AHP method in the decision-making process in the dimensioning of the US Marine Fleet. As an example of the AHP method application in the military systems there is an application of AHP method in the decision-making in engagement of the units based on available information inputs (Minutolo 2003). Dağdeviren et al. (2009) have used AHP method in the combination with TOPSIS method in the process of type of armament selection, while Bahadori et al. (2014) did the analysis of the quality of the health care services in the chosen military hospitals in Iran. The aim of this study was to make an evaluation of the quality of health care service in the chosen hospitals in Iran using AHP, and make its ranking. The application of the AHP method in the Serbian Armed Forces can be observed through the works such as AHP as a support to the envelopment group in defence operations (Božanić et al. 2018) and the method modification of the AHP and its application in decision-making in the defence system Bojanic et al. (2018), noting that AHP method, for the vehicle selection problem solving has not been used in the Serbian Armed Forces yet.

As abovementioned, AHP method can be successfully applied in combination with DEA model. DEA can be considered as a specially designed technique for the efficiency measuring and observing of organizational units, which are defined as DMU. DEA in operational research was introduced by Charnes et al. (1978) and advanced by Banker et al. (1984). Since 1978 more than 1000 publications, books and dissertations have been published which prove the successful use of DEA models. DEA analysis application in the science literature in first 30 years is presented within "Evaluation of research in efficiency and productivity..." (Emrouznejad et al. 2008).

DEA technique is applied in many fields and spheres of life as in, education, health, agricultural production, banking, defence forces, sport, economy, transport, etc. For example, Managi and Karemera (2004) developed DEA technique for the agricultural productivity measuring in the US. Lindebo (2004) suggested DEA method for the economic capacity estimation of Danish Fishing Fleet and Ilić and Petrevska (2018) applied DEA method in estimation of tourism efficiency in Serbia and the neighbouring countries. Beside the mentioned, DEA technique is frequently applied simultaneously with AHP method (Ramanathan 2006; Wang et al. 2008), estimation of efficiency in elementary schools in Indonesia (Fatimah, Mahmudah 2017). Yang (2006) in his work used DEA method for the total effects estimation in Canadian life and health care insurance, while Zavras et al. (2002) used DEA for the efficiency estimation in Greek Prime Health Network, while in military systems the DEA technique can be seen within the unit efficiency measuring for maintenance in American Air Forces (Charnes et al. 1984), efficiency analysis of medical resource use in American Army (Charnes et al. 1985).

\section{Hybrid AHP-DEA model}

In this paper a hybrid AHP-DEA model is presented, combining and emphasizing individual advantages of an AHP-DEA model (Figure 1).

In the first phase, through the aplication of AHP model an expert evaluation of criteria and initial ranking of alternatives is done. At the exit of AHP model, besides the initial alternative ranking, there are inter-ranking alternatives by each criteria of the first hieararchy level. Interranking alternatives are determined on the basis of weight factors of the first level criteria. The values of weight factors also represent the output data from AHP models, which are further processed through algorythm of DEA model in the second phase of algorythm. As the output of the second phase the results are efficiencies of DMUs (alternatives), that is ranking alternatives by DEA model.

For the purpose of confirmation of obtained results, after phase I and II of algorithm, a sensitivity analysis of obtained results to the change of weight factors is done, as 


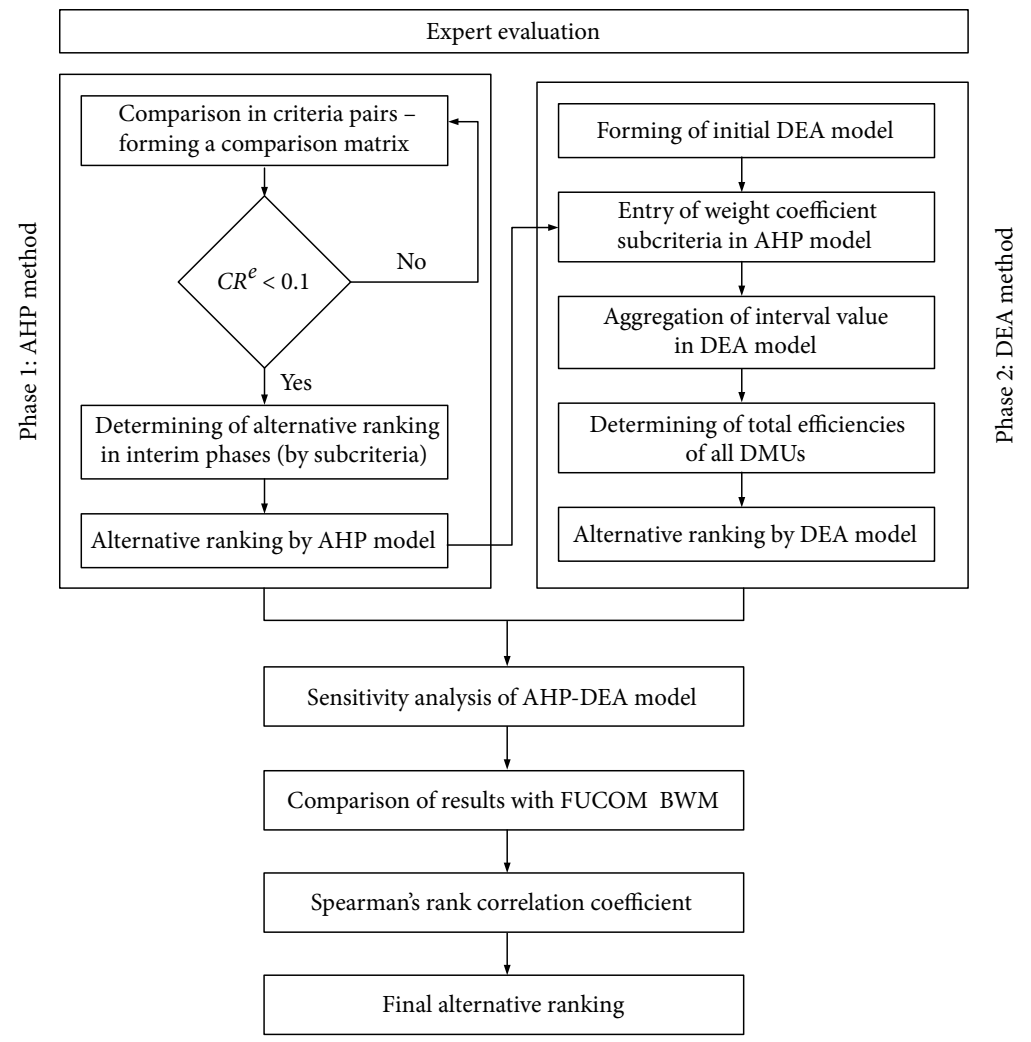

Figure 1. Hybrid AHP-DEA model

well as validation of results through application of other models (FUCOM and BWM). Given results are statistically processed by applying Spierman's correlation coefficient and on the basis of a conducted statistical analysis, the final ranking of alternatives is defined.

\subsection{AHP method}

As one of the most popular methods in multicriteria decision-making, AHP is widely used in different problems of decision-making, especially in solving problems of critieria weighting factors (Pamučar et al. 2018c). It enables estimation of consistency of expert preferences in a group decision-making and enables manipulation with qualitative and quantitatve criteria.

Methodologically viewed, AHP method presents multicriteria technique based on complex problem decomposing in the hierarchy. In global hierarchy, a structured model of decision-making consists of: goals, criteria, few levels of sub-criteria and alternatives (Figure 2). The goal is at the top and it does not compare with any other element (Nunić 2018).

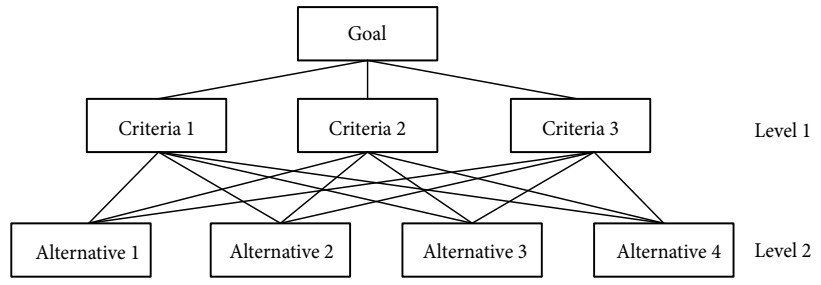

Figure 2. Hierarchical example in AHP
On the level 1, there are $n$ criteria, which are compared with one another, two at the time with respect to their impact on an element above. The same method is repeated down the hierarchy, and at the end a synthesis of all evaluations is done according to the weight coefficient of each element of the hierarchy using the strictly determined mathematical model. Since it is a well-known methodology, presented in many papers (Gigović et al. 2016; Pamučar et al. 2018a, 2018d; Stojić et al. 2018, etc.), authors are not trying to present the methodology of AHP again, but in following chapters emphasis is on the practical application and discussion of obtained results.

\subsection{DEA method}

In this paper DEA method will be applied using the results obtained by AHP method. The assumption is that there are $n$ potential alternatives in the hierarchical model. It is assumed that there are also $m$ criteria. So let $w_{i j}$ present priority of $i$-alternative compared to $j$ criteria, which is a result of the adequate comparison within the AHP method $(i=1, \ldots, n, j=1, \ldots, m)$. To obtain the result of $k$ potential alternatives the suggested DEA model (for each $k=1, \ldots, n$ ) is (Managi, Karemera 2004):

$$
\begin{aligned}
& z_{k}^{*}=\max \sum_{j=1}^{m} w_{k j} \cdot u_{j}, \\
& \text { subject to: } \sum_{j=1}^{m} w_{i j} \leq 1, i=1, \ldots, n, \\
& u_{j} \geq \varepsilon, j=1, \ldots, m,
\end{aligned}
$$


where: $z_{k}^{*}$ is a result for $k$ alternative $(k=1, \ldots, n) ; \varepsilon$ is non-Archimedean; also, each potential alternative we define as DMU and AHP priority weight $w_{i j}$ like $j$ output of $i$ alternative $(i=1, \ldots, n, j=1, \ldots, m)$.

It could be seen that in such a defined task there is only $m$ output with no input. In order to compare all the alternatives we assume that all DMU alternatives have the same amount of inputs, which is called dummy input (Emrouznejad et al. 2008). Now there is a possibility for above mentioned DEA model to be applied in the terrain vehicle selection, for the unit equipping purposes.

For the detailed presentation of DEA algorithm authors recommend papers - Ramanathan (2006), Wang et al. (2008), Lukovac et al. (2017) and Stević et al. (2017).

\section{Applying of a hybrid AHP-DEA model for terrain vehicle selection for the needs of military units engaged in multinational operations}

Nowadays, the international community is facing the crises and conflicts, which, if not controlled present a real threat to the regional and national security. According to that, the need for the joint approach to the security, based on dialogue, partnership, coordinated actions and joint activities by the international subjects in the field of security and defence is more evident. One of the most important missions of most armed forces in the world surely is an active contribution to the global peace and security, mutual trust strengthening and individual abilities developing for the joint response to the security challenges. Multinational operations are military actions taken within the system of collective security and defence, according to the international law and approved international conventions. Members of Serbian Armed Forces can be involved in the multinational operations across the borders of the Republic of Serbia, as following:

- peace keeping, observance and world peace building operations;

- conflict preventions and peace establishing;

- joint defence operations in accordance with defence conventions;

- operations in eliminating the consequences of international terrorism and greater terrorist acts;

- participating in humanitarian operations in cases of natural disasters, major technical-technological and ecological disasters and first aid in critical situations.

Multinational operations across the borders of the Republic of Serbia in which the Serbian Armed forces are engaged are:

- UN multinational operation in the DR Congo (MONUSCO);

- UN multinational operation in Liberia (UNMIL);

- UN multinational operation in the Ivory coast (UNOCI);

- UN multinational operation in the Republic of Cyprus (UNFICYP);

- UN multinational operation in the Republic of Lebanon (UNIFIL);
- UN multinational operation in the Near East (UNTSO);

- UN multinational ooperation in the Central African Republic (MINUSCA);

- EU multinational operation (EUTM Somalia);

- military operation of EU Naval forces in Somalia;

- EU multinational operation in the Central African Republic (EUFOR RCA);

- EU mission for the training of the military and security forces of Mali (EUTM Mali).

Type of tasks performed by units engaged in multinational operations demand high level of unit mobility, that is the ability to deploy forces in short time with keeping the required level of usability of a unit. Successful use of forces in the multinational operations above all is provided by the well-trained and well-equipped units, which are there to accomplish their mission. One of the parameters, which could affect the accomplishment of the given tasks in the multinational operation is the existence of adequate logistic system, whose functioning mainly depends on the means of transport used for the units equipping. Equipping with highly serviceable terrain vehicles, which can move above the communicational range enables units to react quickly and successfully, to dislocate and be ready to react in a very short time during training in multinational operation (Zinaja, Arsić 2011). By using scientific methods, in this case by applying AHP-DEA model, on the basis of relevant criteria and procedures, conditions are created to accomplish the optimal selection of transport vehicles to be used for equipping of units engaged in multinational operations. According to that, units will be eqipped with high-performance terrrain vehicles, with engines of adequate characteristics (power, consumption, cylinder capacity), required payload, high obstacle overcoming, and with the required level of ballistic protection, and presence of modern systems for active and passive protection of vehicles. With that kind of vehicle selection, ability and efficiency are primarily improved, but at the same time safety and flexibility of units in performing all tasks within multinational operations.

The most important characteristics of Serbian Armed Forces vehicles are (Zinaja, Arsić 2011): too many different types of vehicles in use, negative age structure - taking into account the projected usage time, constant maintenance cost rising, insufficient number of vehicles equipped with modern systems (GPS, means of communication, etc.) and vehicle supplying in the previous period was not in line with the budgeting.

\subsection{Hierarchical model}

In the Figure 3 there is a hierarchical model with four levels of selection of the terrain vehicle for the needs of units engaged in multinational operations.

The first level presents a goal, which is a selection among the offered type of vehicles, while the second level presents 8 criteria for the vehicle selection: vehicle characteristics, vehicle payload, engine characteristics, vehi- 
cle equipment, budgeting, maintenance, guarantee and protection. The third level consists of 25 sub-criteria of the main criteria, while the potential types of vehicles are shown on the fifth level.

Specific conditions of military vehicles engagement in multinational operations demand a broader and more systematic approach in the process of defining potential alternatives, that is vehicle types that should be taken into consideration for equipping of military units to be engaged in multionational operations. According to that, for the purpose of the right selection of potential alternatives it is necessary to define principles, that is guidelines on the basis of which selection will be made. In the first place, it should be taken into consideration that units must be trained and equipped primarily for performing military missions, which requires high-performance vehicle engines, adequate payload and mobility in obstacle overcoming, high level of protection of the load and people etc. Besides all said, considering the fact that units are engaged out of the territory of Republic of Serbia, it is necessary to provide vehicles with sophisticated navigation systems and a regulated system of vehicle maintenance, spare part provisions and equipping during engagement. Also, an important condition is presented with the fact that tasks in multinational operations are most frequently conducted in cooperation with armed forces of other countries, so obtained vehicles must be compatible with vehicles and equipment of foreign army units regarding maintenance, spare parts etc. Finally, one of the factors to be considered during vehicle selection is costing and delivery period. With all abovementioned specific conditions of units engaged in multinational operations, in joint cooperation with professionals employed in the armed forces, who are in charge of transport and traffic and also with officers with experiences in multinational operations, following guidelines are defined for choosing potential alternatives in selection of vehicles for equipping of units engaged in multinational operations:

- the vehicle needs to be selected according to the competitive price and the best performances;

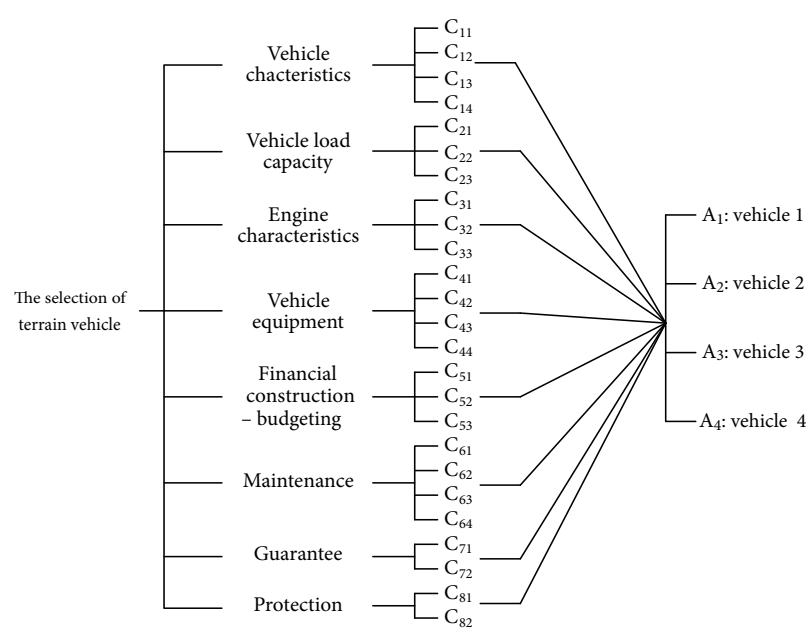

Figure 3. Hierarchical model for the vehicle selection
- the chosen vehicle needs to meet military standards regarding people and load protection, the terrain condition usage and others;

- the delivery of the selected vehicle needs to be in the shortest possible period;

- the supplier should provide technical support after the vehicle delivery.

Applying the listed guidelines in the process of market analyzing, four types of vehicles have been selected as potential alternatives for the military units equipping, the units engaged in task accomplishing in the multinational operations in the world. What is important to point out is that in this specific case, according to the prescribed safety and protection procedures and the data protection, the vehicles will be marked as "Vehicle 1", "Vehicle 2", "Vehicle 3" and "Vehicle 4":

- "Vehicle 1": has all required technical characteristics. 4 people can be transported in the vehicle at the same time, the level of the passengers and load protection is on the higher level compared to the other offered types of vehicles. Cylinder capacity of the engine is $6500 \mathrm{~cm}^{3}$ with the engine power of $190 \mathrm{hp}$ and fuel consumption of $23.75 \mathrm{l} / 100 \mathrm{~km}$. The price of the vehicle is 157851.00 USD. For the purchase of this type of vehicle better buying conditions can be applied for. The delivery period is 6 months and guarantee for delivered parts is 24 months. The offer covers a certain amount of the spare parts for the vehicle maintenance or the resources for the vehicle servicing. The armed forces have no trained personnel or the maintenance resources so the vehicle servicing is necessary to be outsourced;

- "Vehicle 2": has all required technical characteristics. 6 people can be transported in the vehicle at the same time, passenger and load protection is on a high level. Cylinder capacity of the engine is $2400 \mathrm{~cm}^{3}$ with the engine power of $122 \mathrm{hp}$ and fuel consumption of $10.1 \mathrm{l} / 100 \mathrm{~km}$. The price of the vehicle is 137025.00 USD. For the purchase of this type of vehicle better buying conditions can be applied for. The delivery period is 4 months, and guarantee for delivered parts is 24 months. The armed forces have trained personnel and resources for the vehicle maintenance up to the level of overhaul;

- "Vehicle 3": has all required technical characteristics. 4 people can be transported in the vehicle at the same time, passenger and load protection is on the lower level compared to "Vehicle 1"and "Vehicle 2". Cylinder capacity of the engine is $2800 \mathrm{~cm}^{3}$ with the engine power of $177 \mathrm{hp}$ and fuel consumption of $10.4 \mathrm{l} / 100 \mathrm{~km}$. The price of the vehicle is 142100.00 USD. For the purchase of this type of vehicle better buying conditions can be applied for. The delivery period is 4 months, and 12 months of guarantee. The armed forces have no trained personnel or resources for the vehicle maintenance so the vehicle servicing is necessary to be outsourced; 
- "Vehicle 4": Has all required technical characteristics. 6 people can be transported in the vehicle at the same time, the level of passenger and load protection is on the lowest level if compared to the other types of vehicles. Cylinder capacity of the engine is $4461 \mathrm{~cm}^{3}$ with the engine power of $268 \mathrm{hp}$ and fuel consumption of $9.5 \mathrm{l} / 100 \mathrm{~km}$. The price of the vehicle is 103800.00 USD. For the purchase of this type of vehicle better buying conditions can be applied for. The delivery period is 6 months, and 60 months of guarantee. The armed forces have no trained personnel or resources for the vehicle maintenance so the vehicle servicing is necessary to be outsourced.

\subsection{Criteria and sub-criteria defining}

In the process of vehicle selection, there are different alternative results, which depend on the nature of the tasks where the vehicles are going to be engaged. So to say, the alternatives are offers, types of vehicles with certain characteristics, which need to satisfy unit's needs. Sub-criteria are attributes for the description of the offered alternatives so to say criteria, which show how much some alternative respond to the certain goal. The right selection of the criteria and sub-criteria presents one of the key steps in the process of AHP method application in the vehicle selection. In his work Byun (2001) as base criteria together with its sub-criteria defines: exterior (style, type, size, type of colour, instrumental panel, etc.), comfort (equipment, operational system, audio system, visibility, interior space) performances (break grab, sound, control, speed, fuel tank capacity, comfort, moment of force, etc.), safety (passengers safety, safety belts, ABS alarm, airbag, anti crush protection, etc.), economic aspects (insurance, re selling value, fuel, price and equipment, etc.), dealer (expertise, number of visits or calls to persuade the customer to buy a car, trust, etc.) and guarantee (customer's satisfaction, servicing time, spare parts, service stations, etc.).

Authors (Apak et al. 2012) in their paper define seven criteria as criteria, which should help customers in decision-making when buying a luxurious car: quality, reliability, technology, image of the type, flexibility, performances and price. Because the presence of too many criteria complicates the process and it takes more time to make a decision, the number of criteria should be reduced to the optimal number. In accordance with the recommendation given by the experts there are 8 criteria and 25 sub-criteria defined to be used for the validation and evaluation of the recommended types of terrain vehicles (Table 1).

Table 1. Main criteria and sub-criteria

\begin{tabular}{|c|c|c|c|c|c|c|}
\hline Goal & & Criteria & \multicolumn{2}{|r|}{ Sub-criteria } & \multicolumn{2}{|r|}{ Alternatives } \\
\hline \multirow{25}{*}{$\begin{array}{l}\text { The selection } \\
\text { of terrain } \\
\text { vehicle }\end{array}$} & \multirow{4}{*}{$\mathrm{C}_{1}$} & \multirow{4}{*}{ vehicle characteristics } & $\mathrm{C}_{11}$ & speed & \multirow{25}{*}{$\begin{array}{l}\mathrm{A}_{1} \\
\mathrm{~A}_{2} \\
\mathrm{~A}_{3} \\
\mathrm{~A}_{4}\end{array}$} & \multirow{25}{*}{$\begin{array}{l}\text { "Vehicle 1" } \\
\text { "Vehicle 2" } \\
\text { "Vehicle 3" } \\
\text { "Vehicle 4" }\end{array}$} \\
\hline & & & $\mathrm{C}_{12}$ & motion & & \\
\hline & & & $\mathrm{C}_{13}$ & transmission & & \\
\hline & & & $\mathrm{C}_{14}$ & obstacle overcoming & & \\
\hline & \multirow{3}{*}{$\mathrm{C}_{2}$} & \multirow{3}{*}{ vehicle load capacity } & $\mathrm{C}_{21}$ & number of solders with load & & \\
\hline & & & $\mathrm{C}_{22}$ & vehicle load capacity & & \\
\hline & & & $\mathrm{C}_{23}$ & attached vehicle & & \\
\hline & \multirow{3}{*}{$\mathrm{C}_{3}$} & \multirow{3}{*}{ engine characteristic } & $\mathrm{C}_{31}$ & fuel consumption & & \\
\hline & & & $\mathrm{C}_{32}$ & cylinder capacity & & \\
\hline & & & $\mathrm{C}_{33}$ & engine power & & \\
\hline & \multirow{4}{*}{$\mathrm{C}_{4}$} & \multirow{4}{*}{ vehicle equipment } & $\mathrm{C}_{41}$ & active security systems & & \\
\hline & & & $\mathrm{C}_{42}$ & winch & & \\
\hline & & & $\mathrm{C}_{43}$ & air-condition & & \\
\hline & & & $\mathrm{C}_{44}$ & GPS & & \\
\hline & \multirow{3}{*}{$\mathrm{C}_{5}$} & \multirow{3}{*}{ financial construction - budgeting } & $\mathrm{C}_{51}$ & price & & \\
\hline & & & $\mathrm{C}_{52}$ & delivery time & & \\
\hline & & & $\mathrm{C}_{53}$ & payment condition & & \\
\hline & \multirow{4}{*}{$\mathrm{C}_{6}$} & \multirow{4}{*}{ maintenance } & $\mathrm{C}_{61}$ & armed forces capacity & & \\
\hline & & & $\mathrm{C}_{62}$ & service network outside the armed forces & & \\
\hline & & & $\mathrm{C}_{63}$ & road assistance & & \\
\hline & & & $\mathrm{C}_{64}$ & spare parts & & \\
\hline & \multirow{2}{*}{$\mathrm{C}_{7}$} & \multirow{2}{*}{ guarantee } & $\mathrm{C}_{71}$ & guarantee terms & & \\
\hline & & & $\mathrm{C}_{72}$ & types of guarantee & & \\
\hline & \multirow{2}{*}{$\mathrm{C}_{8}$} & \multirow{2}{*}{ protection } & $\mathrm{C}_{81}$ & passive safety & & \\
\hline & & & $\mathrm{C}_{82}$ & level of person and load protection & & \\
\hline
\end{tabular}




\subsection{AHP weight determination}

Figure 3 shows an offered hierarchical model for the terrain vehicle selection with defined criteria and 25 sub-criteria used for the validation of four potential alternatives. After hierarchy structuring, the next step presents a relative weight determination (or priorities) of all criteria. For the weight factor evaluation, to say importance of two criteria, in AHP method Saaty's scale of evaluation (Table 2) is used.

The evaluation of the criteria importance is done by Saaty's scale and in cooperation with experts in the armed forces (Table 3).

For the relative weight determining (or priorities) of each criteria it is used expert choice, one of the most efficient tools for the multicriteria problem solving. Applying expert choice and AHP method in the multi criteria problem solving is the topic earlier explained in reseach by Ishizaka and Labib (2009). After using expert choice software and after the comparison, we have reached the following weight criteria values (Figure 4).

The results present defined weight criteria values, which are used to conclude that the "Financial construction - budgeting" (0.259) is the most important criteria, then "Maintenance" (0.208), while the weakest criteria value is "Vehicle characteristics" (0.057). Also, in the Figure 4, it can be seen that consistency takes the value of 0.03 with the conclusion that the result is correct enough and that there is no need for corrections in comparison and conclusion repetition. After the first level criteria ranking, the second level criteria ranking needs to be done, that is to say sub-criteria. The results are presented in the following figures (Figures 5-12).

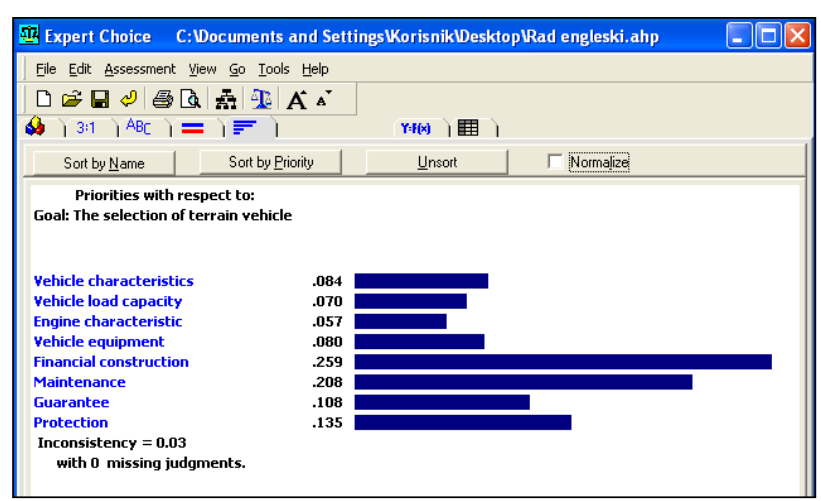

Figure 4 . The values of the defined weight criteria

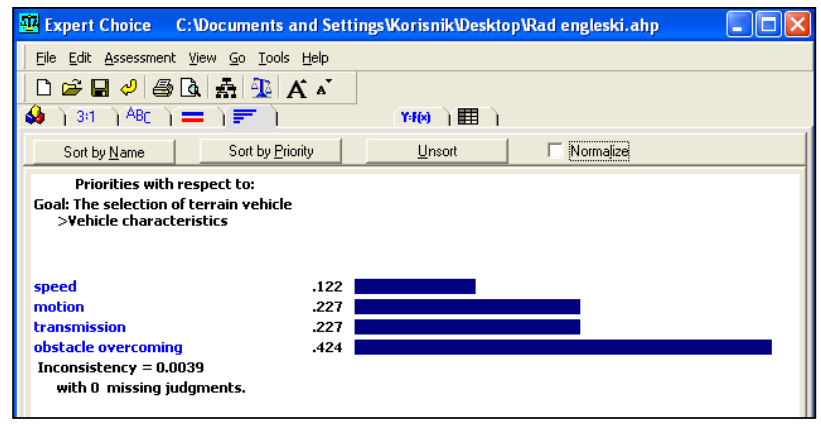

Figure 5. Vehicle characteristics

Table 2. Saaty's scale of evaluation

\begin{tabular}{|c|l|l|}
\hline Importance & \multicolumn{1}{|c|}{ Definition } & \multicolumn{1}{c|}{ Explanation } \\
\hline 1 & the same meaning & two elements are of identical importance in relation to the goal/objective \\
\hline 3 & weak dominance & one element is slightly favoured compared to the other \\
\hline 5 & strong dominance & one element is significantly favoured compared to the other \\
\hline 7 & demonstrated dominance & dominance of one element is practically proved \\
\hline 9 & absolute dominance & the highest level of dominance \\
\hline $2,4,6,8$ & mean value & compromise needed or further selection \\
\hline
\end{tabular}

Table 3. Weight criteria comparison

\begin{tabular}{|c|c|c|c|c|c|c|c|c|}
\hline Name of criteria & 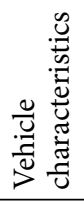 & 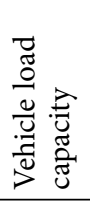 & 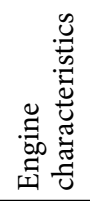 & 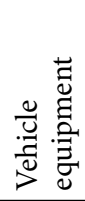 & 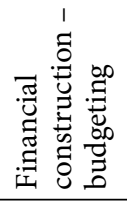 & 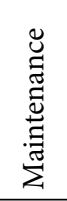 & 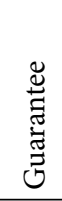 & 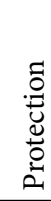 \\
\hline Vehicle characteristics & 1 & 2 & 1 & 1 & $1 / 3$ & $1 / 3$ & 1 & $1 / 2$ \\
\hline Vehicle load capacity & $1 / 2$ & 1 & 2 & 1 & $1 / 3$ & $1 / 3$ & $1 / 2$ & $1 / 2$ \\
\hline Engine characteristics & 1 & $1 / 2$ & 1 & $1 / 2$ & $1 / 3$ & $1 / 3$ & $1 / 2$ & $1 / 2$ \\
\hline Vehicle equipment & 1 & 1 & 2 & 1 & $1 / 3$ & $1 / 2$ & $1 / 2$ & $1 / 2$ \\
\hline Financial construction - budgeting & 3 & 3 & 3 & 3 & 1 & 2 & 3 & 2 \\
\hline Maintenance & 3 & 3 & 3 & 2 & $1 / 2$ & 1 & 3 & 2 \\
\hline Guarantee & 1 & 2 & 2 & 2 & $1 / 3$ & $1 / 3$ & 1 & 1 \\
\hline Protection & 2 & 2 & 2 & 2 & $1 / 2$ & $1 / 2$ & 1 & 1 \\
\hline
\end{tabular}




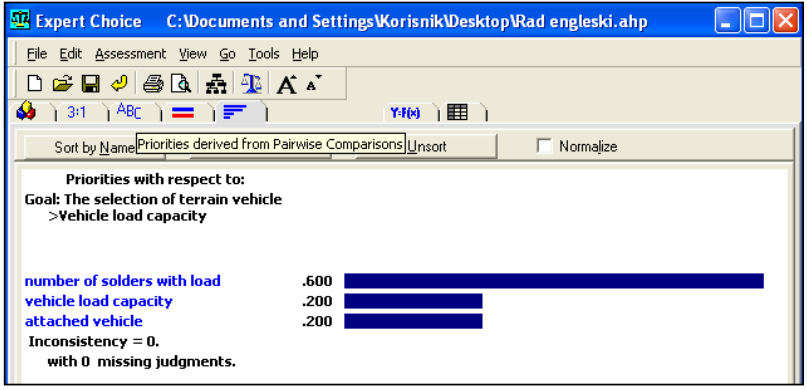

Figure 6. Vehicle load capacity

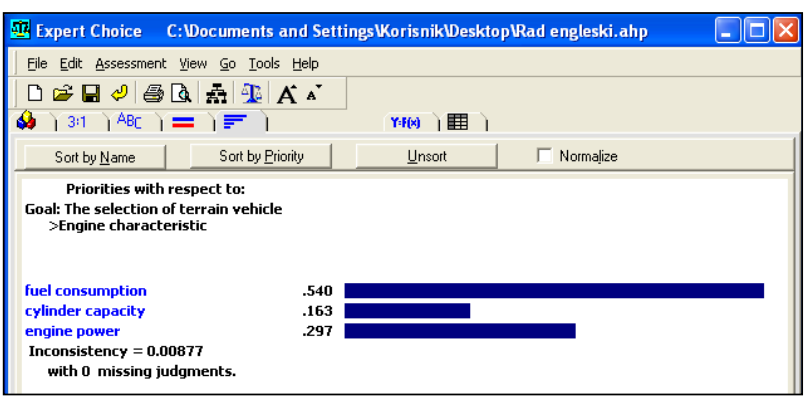

Figure 7. Engine characteristics

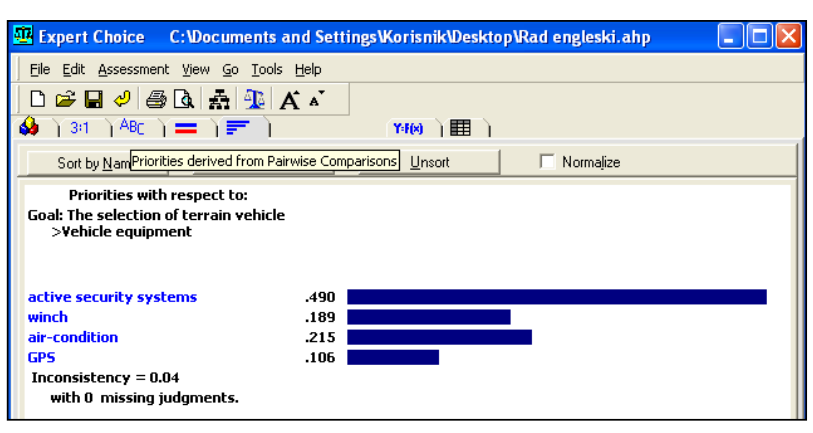

Figure 8. Vehicle equipment

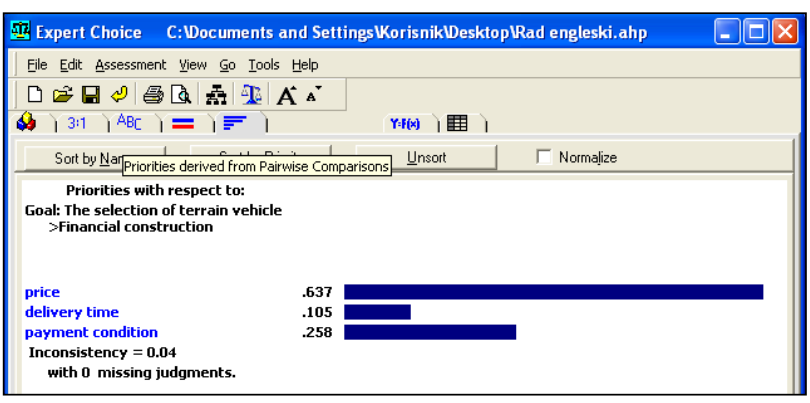

Figure 9. Finacial construction - budgeting

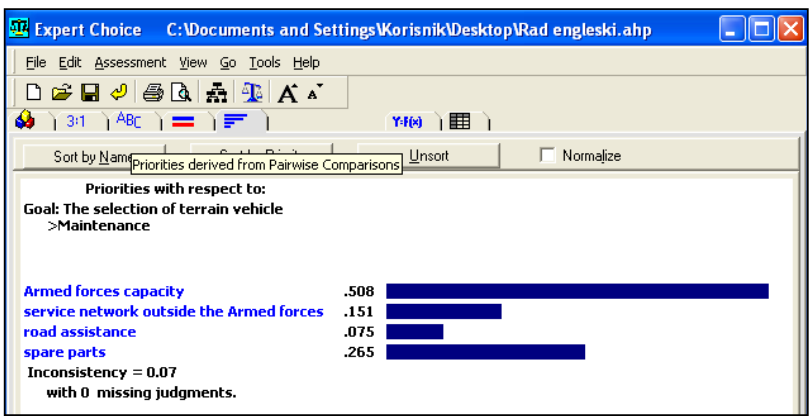

Figure 10. Maintenance

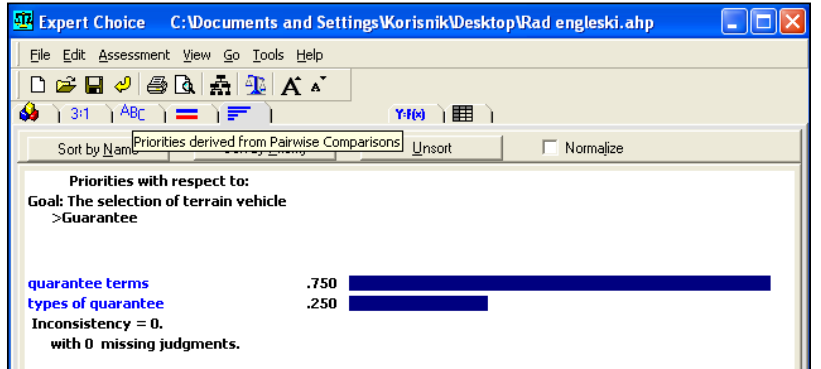

Figure 11. Guarantee

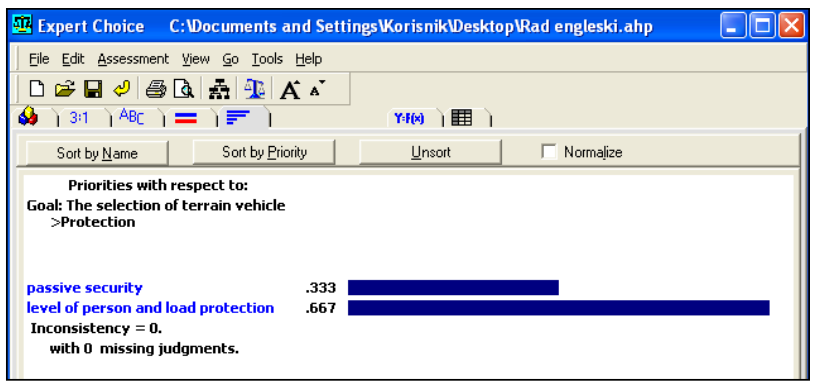

Figure 12. Protection

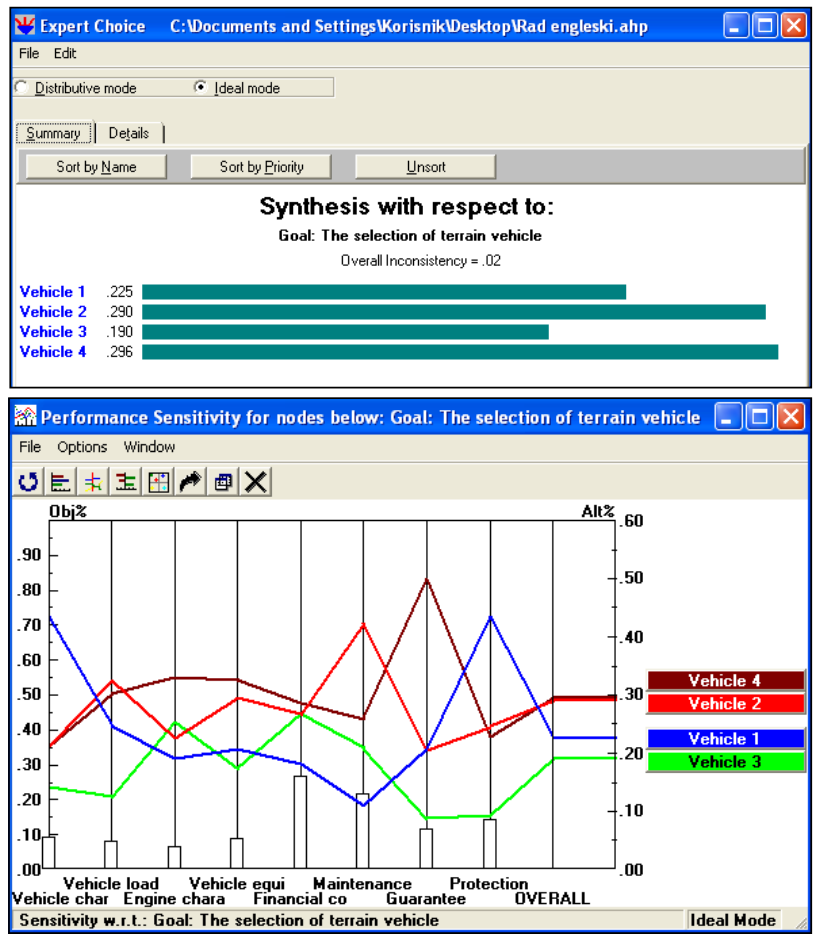

Figure 13. Alternative ranking

After the weight criteria and sub-criteria values defining, we approach the ranking of the offered alternatives, that is we approach the process in which each of the alternatives is evaluated according to the each criteria and sub-criteria. Analyzing the obtained results we have come to the conclusion that, by defined criteria and sub-criteria, "Vehicle 4" presents the best choice (Figure 13 and Table 4). Also, it could be seen that in the Figure 13. the consistency value is 0.02 , which leads us to the conclusion that the result is correct enough. 
Table 4. Alternative ranking obtained by AHP method

\begin{tabular}{|c|c|c|}
\hline \multicolumn{2}{|c|}{ Alternative } & Significance \\
\hline $\mathrm{A}_{1}$ & "Vehicle 1" & 0.225 \\
\hline $\mathrm{A}_{2}$ & "Vehicle 2" & 0.290 \\
\hline $\mathrm{A}_{3}$ & "Vehicle 3" & 0.190 \\
\hline $\mathrm{A}_{4}$ & "Vehicle 4" & 0.296 \\
\hline
\end{tabular}

\subsection{Applying DEA model}

The results obtained by applying AHP method are presented in Table 4 and present the rank of four potential alternatives by the basic criteria, while in Table 5 there are appropriate data for the suggested DEA model (1), where $\mathrm{DMU}_{i}$ presents $i$ alternative $(i=1, \ldots, 4), \mathrm{O}_{j}$ presents $j$ output $(j=1, \ldots, 8)$, that is:

- $\mathrm{O}_{1}$ - priority alternative according to the criteria "Vehicle characteristics";

- $\mathrm{O}_{2}$ - priority alternative according to the criteria "Vehicle load";

- $\mathrm{O}_{3}$ - priority alternative according to the criteria "Engine characteristics";

- $\mathrm{O}_{4}$ - priority alternative according to the criteria "Vehicle equipment";

- $\mathrm{O}_{5}$ - priority alternative according to the criteria " $\mathrm{Fi}$ nancial construction - budgeting";

$-\mathrm{O}_{6}$ - priority alternative according to the criteria "Maintenance";

$-\mathrm{O}_{7}$ - priority alternative according to the criteria "Guarantee";

- $\mathrm{O}_{8}$ - priority alternative according to the criteria "Protection".

Table 5 shows the necessary information for the suggested DEA model. As potential alternatives, so to say potential types of vehicles have more outputs with no inputs, in the last column in the table there is one entry/ input included. Now DEA model will be applied to the first alternative.

$$
\begin{aligned}
& z_{1}^{*}=\max 0.436 \cdot u_{1}+0.247 \cdot u_{2}+0.190 \cdot u_{3}+ \\
& 0.206 \cdot u_{4}+0.180 \cdot u_{5}+0.108 \cdot u_{6}+ \\
& 0.206 \cdot u_{7}+0.434 \cdot u_{8} ; \\
& 0.436 \cdot u_{1}+0.247 \cdot u_{2}+0.190 \cdot u_{3}+ \\
& 0.206 \cdot u_{4}+0.180 \cdot u_{5}+0.108 \cdot u_{6}+ \\
& 0.206 \cdot u_{7}+0.434 \cdot u_{8} \leq 1 ; \\
& 0.212 \cdot u_{1}+0.325 \cdot u_{2}+0.226 \cdot u_{3}+ \\
& 0.295 \cdot u_{4}+0.266 \cdot u_{5}+0.424 \cdot u_{6}+ \\
& 0.206 \cdot u_{7}+0.245 \cdot u_{8} \leq 1
\end{aligned}
$$

$$
\begin{aligned}
& 0.141 \cdot u_{1}+0.125 \cdot u_{2}+0.254 \cdot u_{3}+ \\
& 0.173 \cdot u_{4}+0.266 \cdot u_{5}+0.208 \cdot u_{6}+ \\
& 0.087 \cdot u_{7}+0.093 \cdot u_{8} \leq 1 ; \\
& 0.212 \cdot u_{1}+0.303 \cdot u_{2}+0.330 \cdot u_{3}+ \\
& 0.325 \cdot u_{4}+0.287 \cdot u_{5}+0.260 \cdot u_{6}+ \\
& 0.500 \cdot u_{7}+0.228 \cdot u_{8} \leq 1 ; \\
& u_{j} \geq \varepsilon, j=1, \ldots, 8 .
\end{aligned}
$$

where: $\varepsilon$ presents non-Archimedean, which could be obtained by the following model:

$$
\begin{aligned}
& \varepsilon_{\max }^{*}=\max \varepsilon ; \\
& 0.436 \cdot u_{1}+0.247 \cdot u_{2}+0.190 \cdot u_{3}+ \\
& 0.206 \cdot u_{4}+0.180 \cdot u_{5}+0.108 \cdot u_{6}+ \\
& 0.206 \cdot u_{7}+0.434 \cdot u_{8} \leq 1 ; \\
& 0.212 \cdot u_{1}+0.325 \cdot u_{2}+0.226 \cdot u_{3}+ \\
& 0.295 \cdot u_{4}+0.266 \cdot u_{5}+0.424 \cdot u_{6}+ \\
& 0.206 \cdot u_{7}+0.245 \cdot u_{8} \leq 1 ; \\
& 0.141 \cdot u_{1}+0.125 \cdot u_{2}+0.254 \cdot u_{3}+ \\
& 0.173 \cdot u_{4}+0.266 \cdot u_{5}+0.208 \cdot u_{6}+ \\
& 0.087 \cdot u_{7}+0.093 \cdot u_{8} \leq 1 ; \\
& 0.212 \cdot u_{1}+0.303 \cdot u_{2}+0.330 \cdot u_{3}+ \\
& 0.325 \cdot u_{4}+0.287 \cdot u_{5}+0.260 \cdot u_{6}+ \\
& 0.500 \cdot u_{7}+0.228 \cdot u_{8} \leq 1 ; \\
& u_{j} \geq \varepsilon, j=1, \ldots, 8 .
\end{aligned}
$$

The optimal value of the stated model gives the maximum value of the non-Archimedean $\varepsilon_{\max }=0.40899$, which corresponds to DMUs in Table 5. Taking $\varepsilon=\varepsilon_{\max }=$ 0.40899 we come to defined DEA model solution for all the potential alternatives. The efficiency alternatives results are presented in the Table 6 .

In the Table 6 there are efficiency results for each of four alternatives $\left(\mathrm{DMU}_{i}\right)$ using the suggested DEA model. According to the given results the fourth alternative $A_{4}$, is the only efficient DMU, so the fourth alternative presents the best selection of the terrain vehicle for the use of the units engaged in multinational operations. According to obtained values of efficiencies of $\mathrm{DMU}_{i}$ (Table 6), we can conclude that exit alternatives in DEA model are ranked as following: $A_{4}>A_{2}>A_{1}>A_{3}$.

Analyzing the result given by DEA model and the results by the AHP method in this paper, presented in Table 4, where the fourth alternative has the biggest weight

Table 5. DEA parameters

\begin{tabular}{|c|c|c|c|c|c|c|c|c|c|}
\hline $\mathrm{DMU}_{i}$ & $\mathrm{O}_{1}$ & $\mathrm{O}_{2}$ & $\mathrm{O}_{3}$ & $\mathrm{O}_{4}$ & $\mathrm{O}_{5}$ & $\mathrm{O}_{6}$ & $\mathrm{O}_{7}$ & $\mathrm{O}_{8}$ & Dummy input \\
\hline $\mathrm{DMU}_{1}$ & 0.436 & 0.247 & 0.190 & 0.206 & 0.180 & 0.108 & 0.206 & 0.434 & 1 \\
\hline $\mathrm{DMU}_{2}$ & 0.212 & 0.325 & 0.226 & 0.295 & 0.266 & 0.424 & 0.206 & 0.245 & 1 \\
\hline $\mathrm{DMU}_{3}$ & 0.141 & 0.125 & 0.254 & 0.173 & 0.266 & 0.208 & 0.087 & 0.093 & 1 \\
\hline $\mathrm{DMU}_{4}$ & 0.212 & 0.303 & 0.330 & 0.325 & 0.287 & 0.260 & 0.500 & 0.228 & 1 \\
\hline
\end{tabular}


Table 6. $\mathrm{DMU}_{i}$ efficiency units

\begin{tabular}{|l|c|c|c|c|}
\hline Alternatives $\mathrm{DMU}_{i}$ & $\mathrm{~A}_{1}$ & $\mathrm{~A}_{2}$ & $\mathrm{~A}_{3}$ & $\mathrm{~A}_{4}$ \\
\hline Efficiency & 0.8209 & 0.8994 & 0.5509 & 1 \\
\hline
\end{tabular}

0.296, it can be concluded that the suggested DEA model and AHP method give the same best alternative "Vehicle 4", as well as the same ranking of other alternatives.

\section{Sensitivity analysis and result validation}

Sensitivity analysis is very important for the decision maker to see how the changes in weights of the defined criteria influence the ranking of the offered alternatives. Sometimes the alternative ranking is changed with small changes of weight factors, and because of that, results of methods of multicriteria decision-making are always accompanied by analysis sensitivity to these changes.

It could be said that the justification of the extensive sensitivity analyses procedure lies in the fact that the credibility of the decision-making can be proved, and at the same time we can eliminate the potential risk of inadequate terrain vehicle selection because of the wrong evaluation and comparison in the existing model. Since here we deal with a hybrid multicriteria model (AHP-DEA model) conducted into two phases, sensitivity analysis of the hybrid model is conducted through separate analyses of AHP and DEA models.

\subsection{Sensitivity analysis of AHP model}

\section{All the criteria and sub-criteria have the same weights}

In the specific case, if the values of all criteria are equal, it will not bring about changes in the vehicle ranking between the given alternatives so the "Vehicle 4" in this case again presents the best choice, and ranking of other vehicle types remains the same (Figure 14). Also, it could be seen that in this case the dominance of the alternative "Vehicle 4" is more expressed compared to other offered types of vehicles.

In the case when all the weights of criteria and subcriteria are equal, the rank of the given alternative also remains unchanged. What is characteristic in that case is that the differences between the alternatives are significantly reduced, for example between "Vehicle 1" and "Vehicle 2" (Figure 15).

\section{One of the criteria is significantly the most important}

If criterion "Financial construction - budgeting" is significantly the most important one, sensitivity analysis could be proved by the fact that in practice, when in the process of decision-making in buying vehicles for the needs of Serbian Armed Forces is not performed by multicriteria principle, almost always the main criterion for the decision-making is the price of the vehicle. In this specific example the total criterion weight "Financial construction - budgeting" is increased up to $45.9 \%$ while the other criteria weights are proportionally decreased (Figure 16).

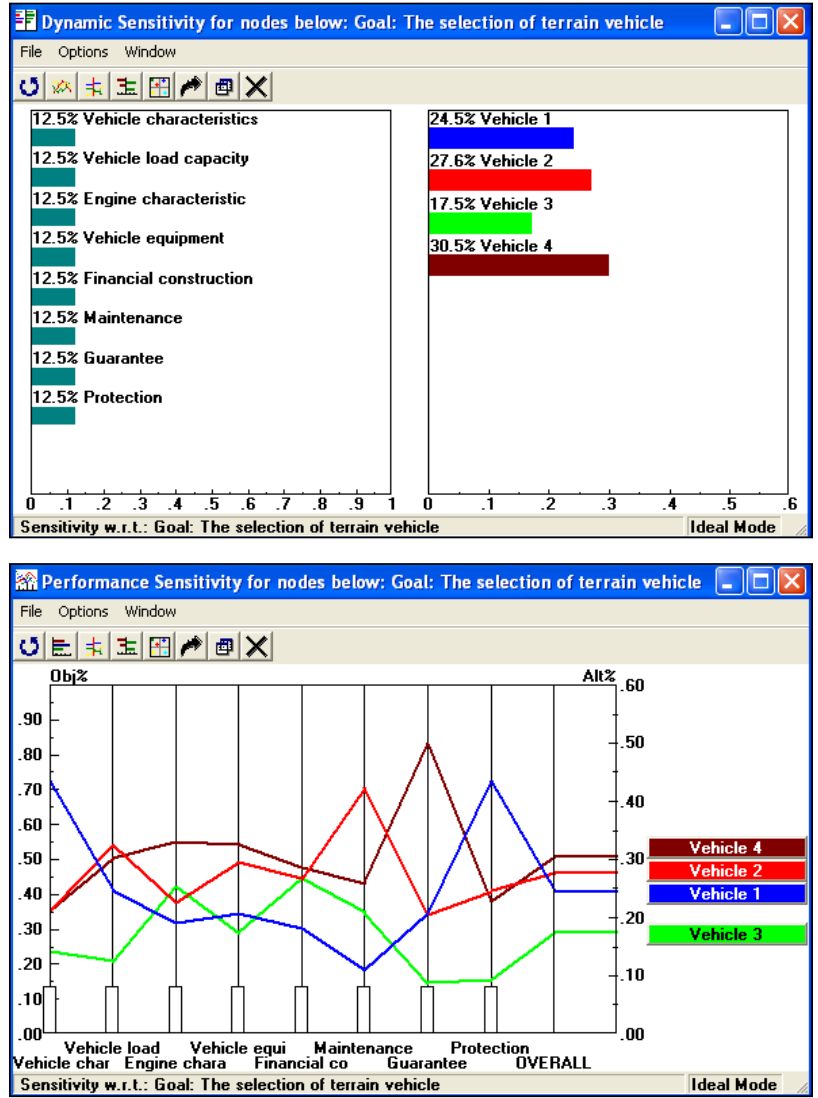

Figure 14. All the criteria have the same weights
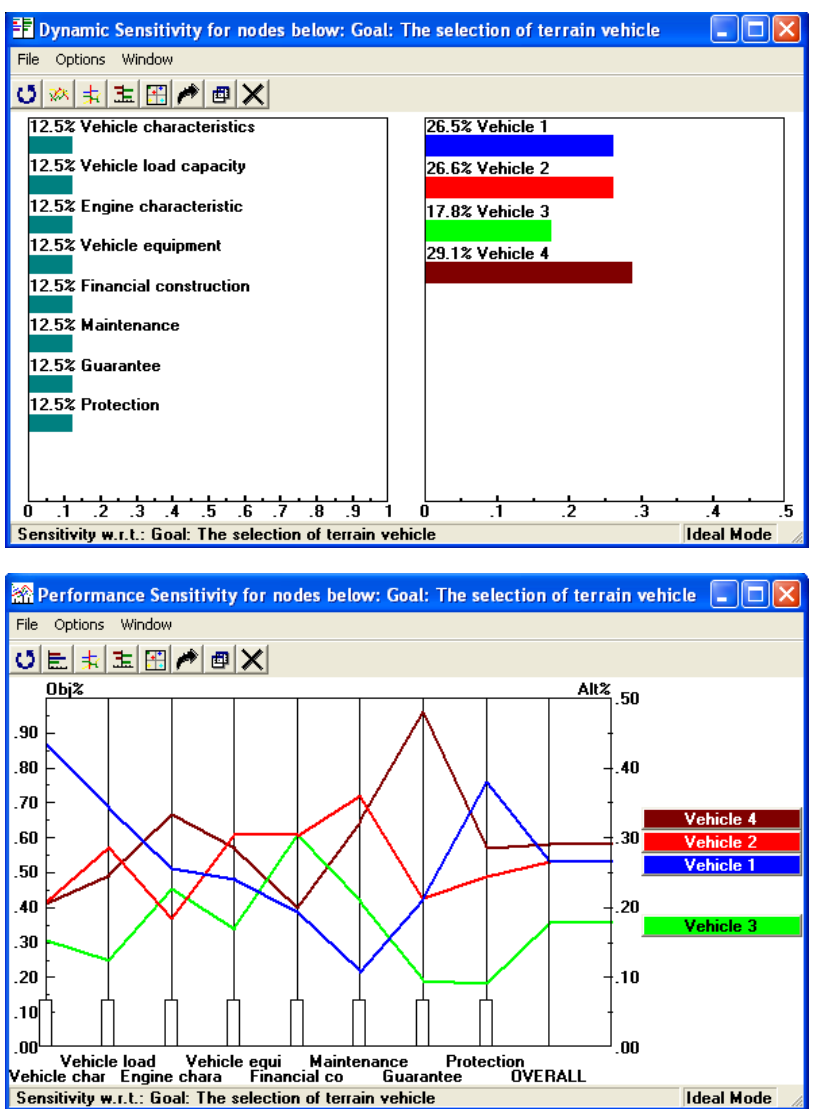

Figure 15. All the criteria and sub-criteria of the same weights 
Analyzing the obtained results it can be seen that the changes in the selection of the cheapest alternative have not changed the output, that "Vehicle 4" still presents the best choice.

In case when "Maintenance" criterion is the most important criterion (Figure 17) it can be observed that it has caused the changes in the selection of the best criterion, that is "Vehicle 2" presents the best choice. Such a result was expected having in mind that the maintenance in the Serbian Armed Forces could be performed only for the "Vehicle 2", while for other types of vehicles maintanace would have to be outsourced.

If the criterion "Protection" is defined as the most important criterion, it will also cause changes in the selection of the best alternative, so in this case "Vehicle 1" presents the best choice (Figure 18). Such a change is due to the fact that the "Vehicle 1" with its characteristics provides significanly the highest level of protection of people and load compared to the other alternatives. An influence of the stated criterion on the final alternative ranking (weight) will surely be greater within AHP models used for the selection of vehicles for the Military operation purposes in the zone of combat operations, where the adequate level of people and load protection in the vehicle is one of the main criteria to be taken into account while making decisions on vehicle selection.

Of course, in this way it is possible to create a great number of different scenarios. Within the conducted sensitivity analysis the change of the weight evaluation of the most important criterion affecting the decision-making in the selection of the terrain vehicle is taken into account and based on the obtained results it can be concluded that the model is well structured.

\section{"Head-to-head "sensitivity analysis}

"Head-to-head"sensitivity analysis presents the difference between two alternatives in regard to the defined criteria. Within this analysis the relation between the best alternative "Vehicle 4" and other offered alternatives will be considered (Figure 19).

"Head-to-head" sensitivity analysis presents "Vehicle 4" compared to "Vehicle 1" to be a better offer according to six defined criteria and a weaker offer according to two defined criteria, with strong dominance by three criteria "Financial construction - budgeting", "Maintenance" and "Guarantee". When "Vehicle 4" and "Vehicle 2" are observed we can see the advantage according to four defined criteria, with significant dominance of "Guarantee" criteria while "Vehicle 2" has significant dominance of "Maintenance" criteria.

Unlike alternatives "Vehicle 1" and "Vehicle 3", the alternative "Vehicle 4" by „Head-to-head" sensitivity analysis has an advantage by all criteria compared to the alternative "Vehicle 3". According to the above stated indicators produced by „Head-to-head“ sensitivity analysis, we can note the dominance of the alternative "Vehicle 4" compared to the other offered types of vehicles by four criteria, which has surely affected the final alternative ranking.

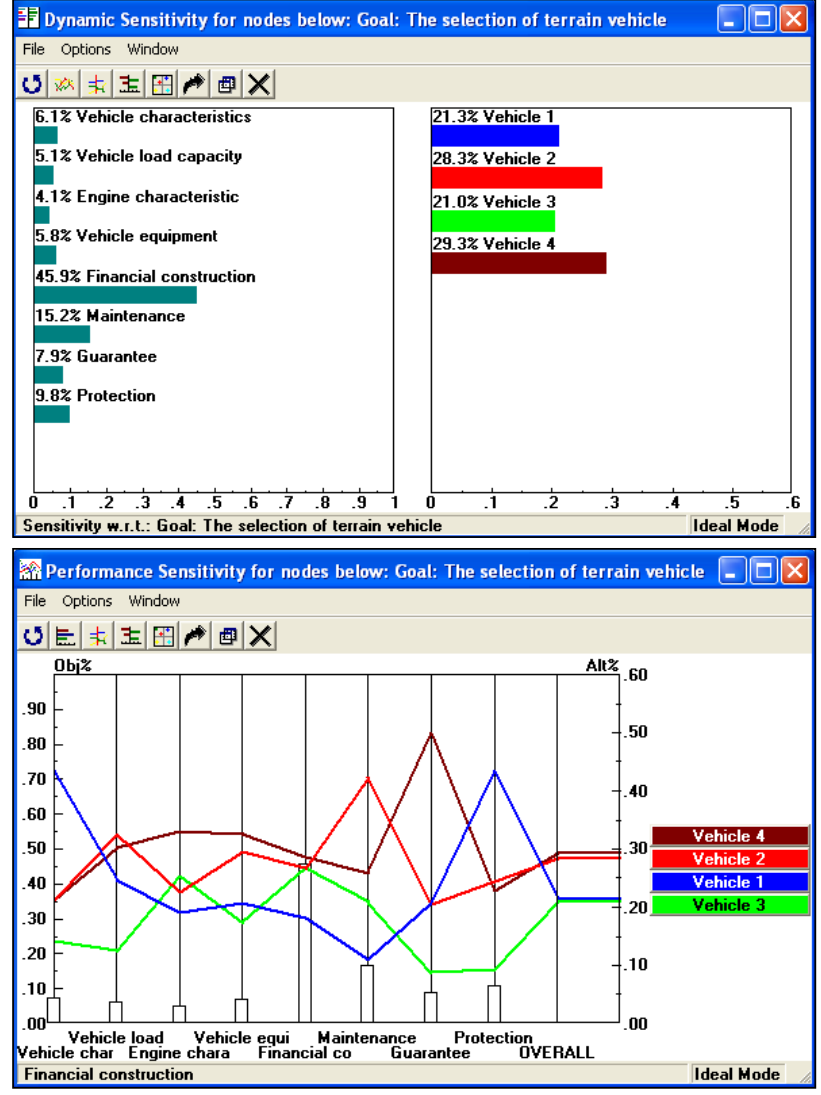

Figure 16. Economic construction is the most important criteria

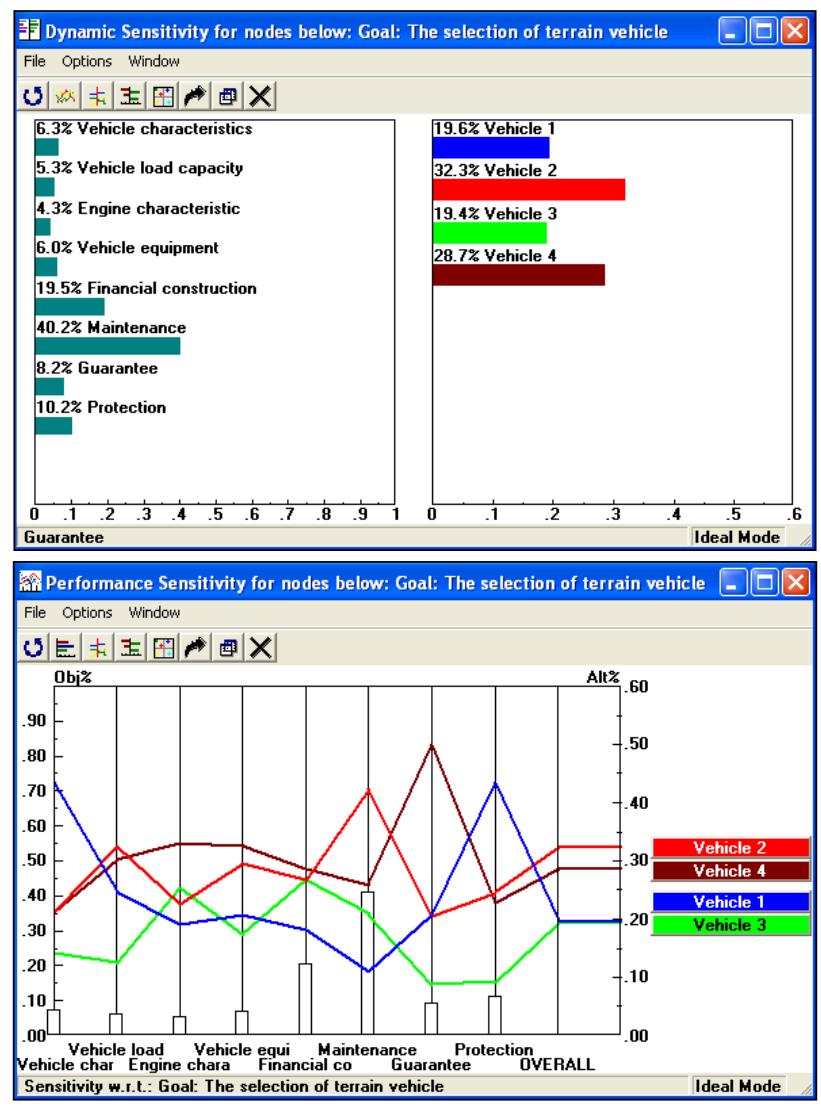

Figure 17. Maintenance is significantly the most important criterion 

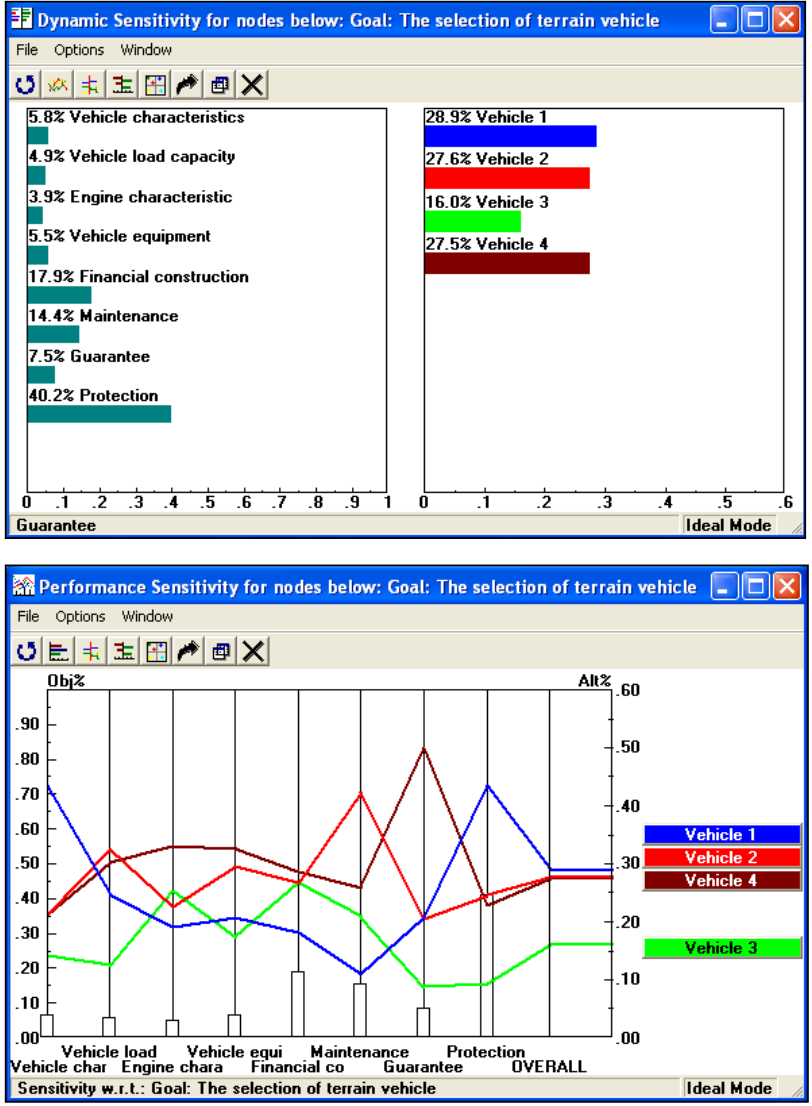

Figure 18. Protection the most important criteria

\subsection{Sensitivity analysis of DEA model}

In the next part, a defined DEA model will be applied to the results obtained with the sensitivity analysis for the given AHP method. In the case when all criteria have equal weights, looking at the data in the Table 7. obtained by AHP method, it can be seen that the values of multi entries remain the same, which leads to conclusion that the weight changes will not affect the results defined by the DEA model (1). This conclusion can be proved by the fact that in the particular case, when weights of all criteria are equal, weights of all alternatives $\operatorname{DMU}_{i}(i=1, \ldots, 4)$ for each defined criterion $\mathrm{O}_{j}(j=1, \ldots, 8)$ remain the same, because their values are obtained by sub-criteria and their values remain the same.

In the case when all criteria and sub-criteria have the same weights (Table 8) it could be seen that the values of multy entries are changed, which leads to the conclusion that value changes of sub-criteria affect the results offered by defined DEA model (1) and that in this case the DEA model applying makes sense.

Using the data from the Table 8 and the non-Archimedean $\varepsilon_{\max }=0.4235$ result, we come to the result of the defined DEA model for all the potential alternatives in the specific case when all the criteria weights and sub-criteria weights are equal. The obtained results of alternative efficiency, in Table 9, show that in this case $\mathrm{A}_{4}$ is the only efficient DMU.

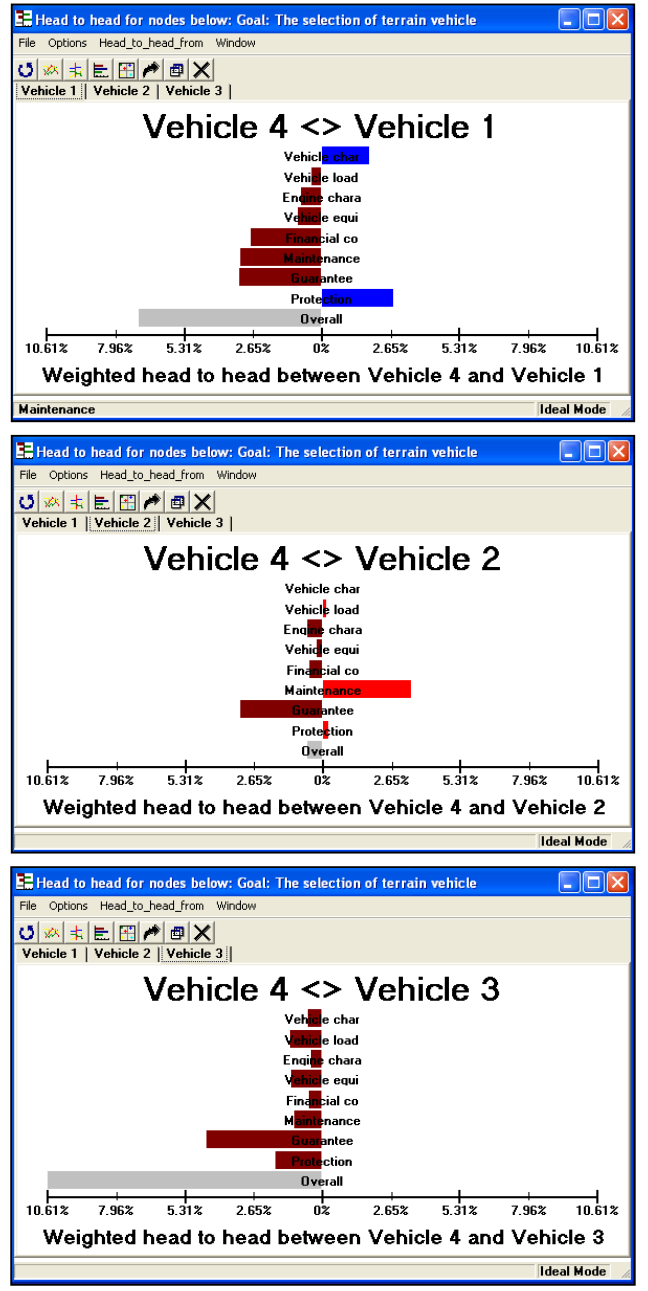

Figure 19. Head-to-head sensitivity analysis

Results (Table 7-9) indicate that assigning different weights to criteria leads to value efficiency according to DMUs, which confirms that this model is sensitive to change of weight factors. By comparing alternative ranks through two presented scenarios (Figure 20), and with results shown in Table 6 , it is confirmed that the alternative $\mathrm{A}_{4}$ is the most efficient and it is of the first rank.

Through rank analyzing we notice that alternative $\mathrm{A}_{4}$ has maintained its ranking as the first one, in both of presented scenarios. According to the obtained results from Table 6 alternative $A_{2}$ is the second ranking, while alternative $A 1$ is the third ranking. In scenario 1 and 2 alternatives $A_{1}$ and $A_{2}$ have changed places, that is alternative $A_{1}$ has become the second ranking, while alternative $A_{2}$ has become the third ranking. In both scenarions alternative $\mathrm{A}_{3}$ has stayed the worst ranking one.

For the purpose of determining the relation between results obtained by applying different scenarios there has been used SCC. Spearman's rank correlation coefficient is an useful and important indicator for determenining the relation between results obtained by sensitivity analysis (Mukhametzyanov, Pamučar 2018). Besides that, SCC is convenient for application in case of ordinal variables or ranking variables, the latter is the case in this study. 
Table 7. DEA parameters when all the criteria weights are equal (scenario 1)

\begin{tabular}{|c|c|c|c|c|c|c|c|c|c|}
\hline $\mathrm{DMU}_{i}$ & $\mathrm{O}_{1}$ & $\mathrm{O}_{2}$ & $\mathrm{O}_{3}$ & $\mathrm{O}_{4}$ & $\mathrm{O}_{5}$ & $\mathrm{O}_{6}$ & $\mathrm{O}_{7}$ & $\mathrm{O}_{8}$ & Dummy input \\
\hline $\mathrm{DMU}_{1}$ & 0.436 & 0.247 & 0.190 & 0.206 & 0.180 & 0.108 & 0.206 & 0.434 & 1 \\
\hline $\mathrm{DMU}_{2}$ & 0.212 & 0.325 & 0.226 & 0.295 & 0.266 & 0.424 & 0.206 & 0.245 & 1 \\
\hline $\mathrm{DMU}_{3}$ & 0.141 & 0.125 & 0.254 & 0.173 & 0.266 & 0.208 & 0.087 & 0.093 & 1 \\
\hline $\mathrm{DMU}_{4}$ & 0.212 & 0.303 & 0.330 & 0.325 & 0.287 & 0.260 & 0.500 & 0.228 & 1 \\
\hline
\end{tabular}

Table 8. DEA parameters when all weight criteria and sub-criteria are equal (scenario 2)

\begin{tabular}{|c|c|c|c|c|c|c|c|c|c|}
\hline $\mathrm{DMU}_{i}$ & $\mathrm{O}_{i}$ & $\mathrm{O}_{2}$ & $\mathrm{O}_{3}$ & $\mathrm{O}_{4}$ & $\mathrm{O}_{5}$ & $\mathrm{O}_{6}$ & $\mathrm{O}_{7}$ & $\mathrm{O}_{8}$ & Dummy input \\
\hline $\mathrm{DMU}_{1}$ & 0.434 & 0.343 & 0.256 & 0.240 & 0.194 & 0.108 & 0.212 & 0.379 & 1 \\
\hline $\mathrm{DMU}_{2}$ & 0.207 & 0.286 & 0.184 & 0.306 & 0.303 & 0.361 & 0.212 & 0.244 & 1 \\
\hline $\mathrm{DMU}_{3}$ & 0.153 & 0.125 & 0.227 & 0.169 & 0.303 & 0.208 & 0.096 & 0.092 & 1 \\
\hline $\mathrm{DMU}_{4}$ & 0.207 & 0.247 & 0.334 & 0.285 & 0.199 & 0.323 & 0.480 & 0.286 & 1 \\
\hline
\end{tabular}

Table 9. $\mathrm{DMU}_{i}$ unit's efficiency when all the criteria and subcriteria weights are equal

\begin{tabular}{|l|c|c|c|c|}
\hline Alternative $\mathrm{DMU}_{i}$ & $\mathrm{~A}_{1}$ & $\mathrm{~A}_{2}$ & $\mathrm{~A}_{3}$ & $\mathrm{~A}_{4}$ \\
\hline Efficiency & 0.9175 & 0.8907 & 0.5816 & 1 \\
\hline
\end{tabular}

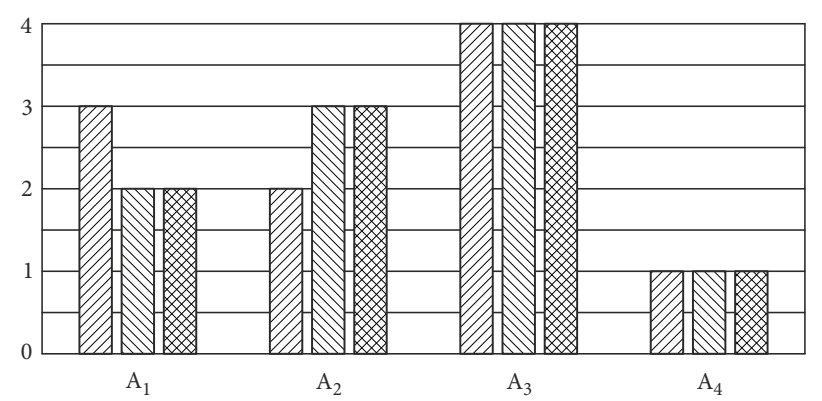

AHP-DEA rank AHP-DEA (scenario 1) AHP-DEA (scenario 2)

Figure 20. Sensitivity analysis of alternative ranking in DEA model

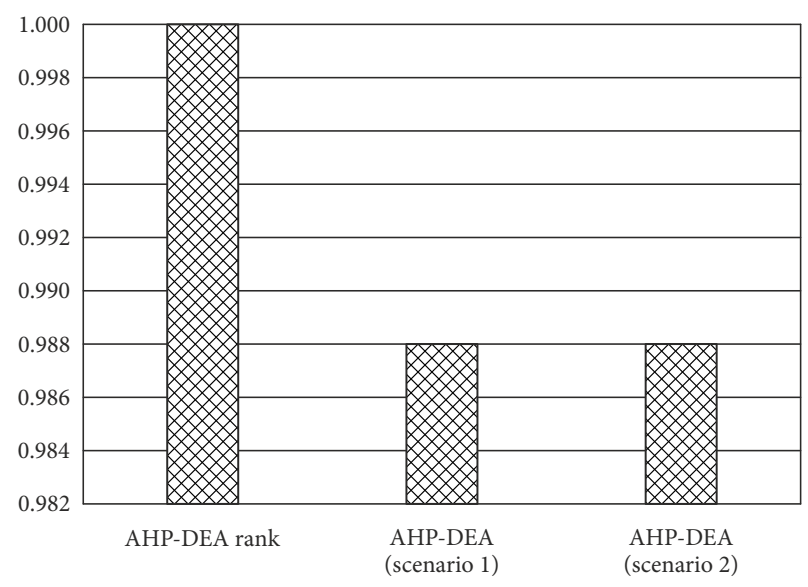

Figure 21. Rank correlation in sensitivity analysis in DEA model
In this paper by applying SCC, statistical importance has been defined of differences between ranks obtained in sensitivity analysis. The results of rank comparisons by applying SCC method are shown in Figure 21.

SCC values form Figure 21 indicate that there is high correlation among ranks obtained in compared methods of multicriteria decision-making. Based on the reccommendations by Stefanović-Marinović et al. (2017) all values of SCC higher than 0.8 indicate extremely high correlation. Since in our case all values of SCC are considerably higher than 0.980 , and the mean value is 0.99 , we can conclude that there is strong correlation between the initial DEA ranking (Table 6) and ranking obtained through the scenarios. According to the presented results we can conclude that the suggested DEA ranking is confirmed and credible.

\subsection{Comparison of results of a hybrid AHP-DEA model with results of other multicriteria techniques}

Validation is conducted through comparison of results of AHP-DEA model with results produced by BWM (Rezaei 2015) and FUCOM (Pamučar et al. 2018c). Presented methods have been selected since they belong to the group of subjective methods for determining weight factor where AHP and DEA method also belong. Besides that, BWM and FUCOM have been selected since they are based on the concept of comparison in criteria pairs and determining the degree of consistency of comparison, which makes the foundation of AHP model. For the purpose of validation of obtained results in this research a comparison has been conducted among ranks in AHP model (Table 4), AHP-DEA model (Table 6), BWM (proposed in this research), FUCOM (proposed in this research), BWM-DEA model (proposed in this research) and FUCOM-DEA model (proposed in this research). Therefore, for the purpose of validation of AHP-DEA model two original models have been formed (BWM-DEA and FUCOM-DEA 
model), which have not been considered so far in literature.

The initial mathematical models for the first level of criteria in BWM and FUCOM models are presendted in the following part:

FUCOM - $\min \chi$ subject to:

$\left\{\begin{array}{l}\left|\frac{w_{5}}{w_{6}}-2\right| \leq \chi,\left|\frac{w_{6}}{w_{8}}-1\right| \leq \chi,\left|\frac{w_{8}}{w_{1}}-1.5\right| \leq \chi,\left|\frac{w_{1}}{w_{2}}-1\right| \leq \chi ; \\ \left|\frac{w_{2}}{w_{3}}-1\right| \leq \chi,\left|\frac{w_{3}}{w_{4}}-1\right| \leq \chi, \ldots,\left|\frac{w_{5}}{w_{8}}-2\right| \leq \chi,\left|\frac{w_{3}}{w_{7}}-1\right| \leq \chi ; \\ \sum_{j=1}^{8} w_{j}=1, w_{j} \geq 0, \forall j .\end{array}\right.$

$\mathrm{BMW}-\min \xi$ subject to:

$\left\{\begin{array}{l}\left|\frac{w_{5}}{w_{6}}-2\right| \leq \xi,\left|\frac{w_{5}}{w_{8}}-2\right| \leq \xi,\left|\frac{w_{5}}{w_{7}}-3\right| \leq \xi,\left|\frac{w_{5}}{w_{7}}-3\right| \leq \xi ; \\ \left|\frac{w_{5}}{w_{1}}-3\right| \leq \xi,\left|\frac{w_{5}}{w_{2}}-3\right| \leq \xi, \ldots,\left|\frac{w_{6}}{w_{5}}-3\right| \leq \xi,\left|\frac{w_{8}}{w_{5}}-2\right| \leq \xi ;(4 \mathrm{~b}) \\ \sum_{j=1}^{8} w_{j}=1, w_{j} \geq 0, \forall j .\end{array}\right.$

In the same way mathematical models are formed for the second level of crtieria, that is for all sub-criteria of a hierarchical model. The exit vectors from BWM and FUCOM models are used further on as entry data in DEA model and the final results of hybrid BWM-DEA and FUCOM-DEA models are obtained (Table 10).

Alternative ranking by abovementioned methods indicate that $\mathrm{A}_{4}$ alternative is the highest ranking, while $\mathrm{A}_{3}$ alternative is the worst by all models. By using AHP, AHPDEA, FUCOM and FUCOM-DEA models the ranking

Table 10. Alternative ranks obtained by BWM, FUCOM, AHP and DEA model

\begin{tabular}{|l|c|c|c|c|c|}
\hline \multicolumn{2}{|c|}{ Method } & \multicolumn{5}{c|}{ Alternative } \\
\cline { 3 - 6 } & $\mathrm{A}_{1}$ & $\mathrm{~A}_{2}$ & $\mathrm{~A}_{3}$ & $\mathrm{~A}_{4}$ \\
\hline \multirow{3}{*}{ AHP } & $w_{j}$ & 0.225 & 0.290 & 0.190 & 0.296 \\
\cline { 2 - 6 } & $\mathrm{rank}$ & 3 & 2 & 4 & 1 \\
\hline \multirow{3}{*}{ AHP-DEA } & $w_{j}$ & 0.821 & 0.899 & 0.551 & 1.000 \\
\cline { 2 - 6 } & rank & 3 & 2 & 4 & 1 \\
\hline \multirow{3}{*}{ BWM } & $w_{j}$ & 0.2017 & 0.189 & 0.1483 & 0.461 \\
\cline { 2 - 6 } & rank & 2 & 3 & 4 & 1 \\
\hline \multirow{3}{*}{ BWM-DEA } & $w_{j}$ & 0.895 & 0.882 & 0.621 & 1.000 \\
\cline { 2 - 6 } & rank & 2 & 3 & 4 & 1 \\
\hline \multirow{2}{*}{ FUCOM } & $w_{j}$ & 0.215 & 0.297 & 0.187 & 0.301 \\
\cline { 2 - 6 } & rank & 3 & 2 & 4 & 1 \\
\hline \multirow{2}{*}{ FUCOM-DEA } & $w_{j}$ & 0.887 & 0.905 & 0.588 & 1.000 \\
\cline { 2 - 6 } & rank & 3 & 2 & 4 & 1 \\
\hline
\end{tabular}

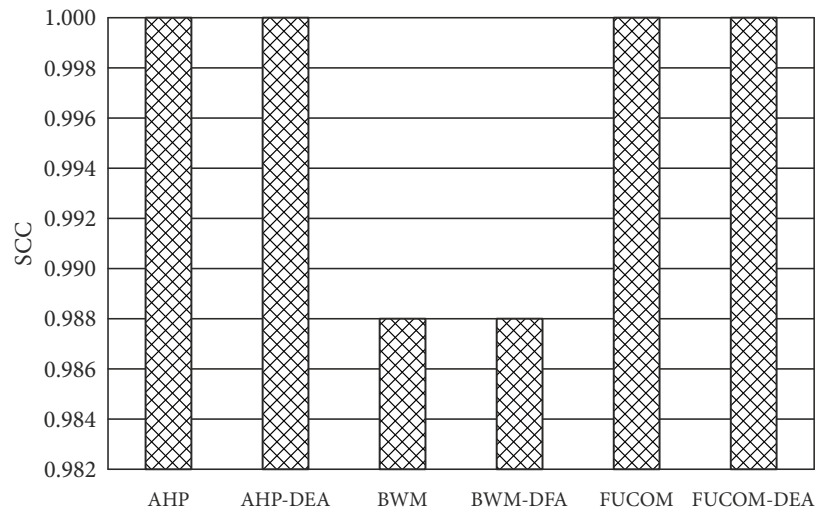

Figure 22. Rank correlataion of model testing

suggested in above has been fully confirmed. With BWM and BWM-DEA models, there has been the change only between the second and third ranking alternative $\left(\mathrm{A}_{2}\right.$ and $\left.\mathrm{A}_{3}\right)$, while the other alternative ranking stayed the same. This analysis supported the results from the previous sections and confirms the choice of $\mathrm{A}_{4}$ alternative as the best one.

As in the previos chapter, SCC has been used for the purpose of determining the relation of results obtained through six different approaches (Table 10). Results of rank comparison through SCC method are shown in Figure 22.

Since the SCC values are considerably higher than 0.98 and the mean value 0.994 , we can say that ranks are highly correlated among all six considered models. On the basis of presented results (Table 10 and Figure 22) we can conclude that suggested ranking is confirmed and credible. Based on the analysis, we can conclude that $\mathrm{A}_{4}$ is the best terrain vehicle.

\section{Conclusions}

In this research there has been created a hybrid AHP-DEA model for evaluation of terrain vehicles for units participating in multinational operations. The presented model enables respecting the subjectivity occurring in the process of a group decision-making through linguistic evaluation of evaluation criteria. Apart from that, through this model presented in the paper there are new methodological foundations introduced for evaluation of transport means in multinational operations, which simultanously contribute to improvement of theoretical foundation of multicriteria decision-making in general.

The research presented in this paper can be used as methodology for decision-making during selcetion of an optimal terrain vehicle. The developed approach enables bridging the existing gap in methodology for terrian vehicle evaluation for the units participating in multinational operations. By selecting optimal terrain vehicles the risk to the unit activities in multionational operatins is significantly reduced, and also their efficiency is considerably improved.

The key contribution of this paper is a new AHP-DEA model for evaluation of transport means in multinational 
operations, as well as a new BWM-DEA and FUCOMDEA models created for the purpose of result validation. A hybrid AHP-DEA model is implemented for evaluation of four transport means considered for use in the Serbian Armed Forces units. For the alternative evaluation eight criteria have been used, which on the second level of hierarchy have been split into twenty-five subcritieria. Obtained results are checked through sensitivity analysis by forming different scenarios simulating weight factors of criteria and applying different approaches developed in the last three years. Model stability is verified through statistical correlation coefficient indicating high rank correlation in all scenarios.

It could be said that this work presents more systematic approach to the multicriteria decision-making problem in military systems then it was a case in the previous period. In the paper we used the wide spectra of criteria, qualitative as well as quantitative, which present the main advantage of this method. Four types of vehicles are evaluated according to eight criteria and twenty-five sub-criteria. According to the chosen criteria and their comparison we have come to the conclusion that the most important criteria are "Financial construction - budgeting" (0.259), "Maintenance" (0.208) and "Protection" (0.135). The evaluation result shows that the "Vehicle 4" is dominant compared to "Vehicle 1" and "Vehicle 1" is significantly dominant compared to "Vehicle 3". The obtained alternative ranking is confirmed also by DEA model application, and its result shows that the alternative $\mathrm{A}_{4}$ ("Vehicle 4") is the only efficient DMU.

AHP-DEA model has certian limitations that can be seen during its implementation, including:

1) not large enough scale (Saaty's scale of relative importance) for pair comparison, related to some decision-making problems;

2) a large number of pair comparisons needed, in most problems;

3) reaching the adequate ratio of consistency is often vey difficult;

4) complexity of mathematical apparatus can be a restricting factor for wide use of model application;

5) impossibility of considering alternatives that are not comparable.

This paper's results will surely contribute to the AHP method application and DEA in the process of multicriteria selection in the military systems. Also, the results can be used in the analysis of the certain criteria influence on the selection of the military vehicle that is systematic approach to path defining in the model of the authority's decision-making, in the process of vehicle selection, in the army as well as in other complex systems.

\section{References}

Adalı, E. A.; Işık, A. T. 2016. Integration of DEMATEL, ANP and DEA methods for third party logistics providers' selection, Management Science Letter 6(5): 325-340. https://doi.org/10.5267/j.msl.2016.3.004
Aghdaie, S. F. A.; Yousefi, E. 2011. The comparative analysis of affecting factors on purchasing domestic and imported cars in Iran market - using AHP technique, International Journal of Marketing Studies 3(2): 142-150.

https://doi.org/10.5539/ijms.v3n2p142

Apak, S.; Göğüş, G. G.; Karakadılar, İ. S. 2012. An analytic hierarchy process approach with a novel framework for luxury car selection, Procedia - Social and Behavioral Sciences 58: 1301-1308. https://doi.org/10.1016/j.sbspro.2012.09.1113

Aull-Hyde, R.; Davis, K. A. 2012. Military applications of the analytic hierarchy process, International Journal of Multicriteria Decision Making 2(3): 267-281.

https://doi.org/10.1504/IJMCDM.2012.047847

Bahadori, M.; Ravangard, R.; Yaghoubi, M.; Alimohammadzadeh, K. 2014. Assessing the service quality of Iran military hospitals: joint commission international standards and analytic hierarchy process (AHP) technique, Journal of Education and Health Promotion 3: 98.

Banker, R. D.; Charnes, A.; Cooper, W. W. 1984. Some models for estimating technical and scale inefficiencies in data envelopment analysis, Management Science 30(9): 1078-1092. https://doi.org/10.1287/mnsc.30.9.1078

Bojanic, D.; Kovač, M.; Bojanic, M.; Ristic, V. 2018. Multi-criteria decision-making in A defensive operation of the guided antitank missile battery: an example of the hybrid model fuzzy AHP - MABAC, Decision Making: Applications in Management and Engineering 1(1): 51-66.

Božanić, D.; Tešić, D.; Milićević, J. 2018. A hybrid fuzzy AHPMABAC model: application in the Serbian army - the selection of the location for deep wading as a technique of crossing the river by tanks, Decision Making: Applications in Management and Engineering 1(1): 143-164.

Byun, D.-H. 2001. The AHP approach for selecting an automobile purchase model, Information \& Management 38(5): 289-297. https://doi.org/10.1016/s0378-7206(00)00071-9

Charnes, A.; Clark, C. T.; Cooper, W. W.; Golany, B. 1984. A developmental study of data envelopment analysis in measuring the efficiency of maintenance units in the U.S. air forces, Annals of Operations Research 2(1): 95-112. https://doi.org/10.1007/BF01874734

Charnes, A.; Cooper, W. W.; Dieck-Assad, M.; Golany, B.; Wiggins, D. E. 1985. Efficiency Analysis of Medical Care Resources in the U.S. Army Health Service Command, Research Report CCS 516, Center for Cybernetic Studies, University of Texas at Austin, TX, US. 25 p.

Charnes, A.; Cooper, W. W.; Rhodes, E. 1978. Measuring the efficiency of decision making units, European Journal of Operational Research 2(6): 429-444. https://doi.org/10.1016/0377-2217(78)90138-8

Chatterjee, P.; Mondal, S.; Boral, S.; Banerjee, A.; Chakraborty, S. 2017. A novel hybrid method for non-traditional machining process selection using factor relationship and multi-attributive border approximation method, Facta Universitatis, Series: Mechanical Engineering 15(3): 439-456. https://doi.org/10.22190/FUME170508024C

Crary, M.; Nozick, L. K.; Whitaker, L. R. 2002. Sizing the US destroyer fleet, European Journal of Operational Research 136(3): 680-695. https://doi.org/10.1016/S0377-2217(01)00031-5

Dağdeviren, M.; Yavuz, S.; Kılınç, N. 2009. Weapon selection using the AHP and TOPSIS methods under fuzzy environment, Expert Systems with Applications 36(4): 8143-8151. https://doi.org/10.1016/j.eswa.2008.10.016

Emrouznejad, A.; Parker, B. R.; Tavares, G. 2008. Evaluation of research in efficiency and productivity: a survey and analy- 
sis of the first 30 years of scholarly literature in DEA, SocioEconomic Planning Sciences 42(3): 151-157.

https://doi.org/10.1016/j.seps.2007.07.002

Fatimah, S.; Mahmudah, U. 2017. Two-stage data envelopment analysis (DEA) for measuring the efficiency of elementary schools in Indonesia, International Journal of Environmental \& Science Education 12(8): 1971-1987.

Giacomini, C.; Longo, G.; Lunardi, A.; Padoano, E. 2016. AHPaided evaluation of logistic and transport solutions in a seaport, in F. De Felice, A. Petrillo, T. Saaty (Eds.). Applications and Theory of Analytic Hierarchy Process: Decision Making for Strategic Decisions, 115-141. https://doi.org/10.5772/63686

Gigović, L.; Pamučar, D.; Bajić, Z.; Milićević, M. 2016. The combination of expert judgment and GIS-MAIRCA analysis for the selection of sites for ammunition depots, Sustainability 8(4): 372. https://doi.org/10.3390/su8040372

Ignaccolo, M.; Inturri, G.; García-Melón, M.; Giuffrida, N.; Le Pira, M.; Torrisi, V. 2017. Combining analytic hierarchy process (AHP) with role-playing games for stakeholder engagement in complex transport decisions, Transportation Research Procedia 27: 500-507.

https://doi.org/10.1016/j.trpro.2017.12.069

Ilić, I.; Petrevska, I. 2018. Using DEA method for determining tourism efficiency of Serbia and the surrounding countries, Hotel and Tourism Management 6(1): 73-80. https://doi.org/10.5937/menhottur1801073I

Ishizaka, A.; Labib, A. 2009. Analytic hierarchy process and expert choice: benefits and limitations, OR Insight 22(4): 201220. https://doi.org/10.1057/ori.2009.10

Lindebo, E. 2004. Trends in the economic capacity of the Danish fishing fleet, 1996-2002, Acta Agriculturae Scandinavica, Section C - Food Economics 1(4): 207-221. https://doi.org/10.1080/16507540410019719

Lukovac, V.; Pamučar, D.; Popović, M.; Đorović, B. 2017. Portfolio model for analyzing human resources: An approach based on neuro-fuzzy modeling and the simulated annealing algorithm, Expert Systems with Applications 90: 318-331. https://doi.org/10.1016/j.eswa.2017.08.034

Managi, S.; Karemera, D. 2004. Input and output biased technological change in US agriculture, Applied Economics Letters 11(5): 283-286. https://doi.org/10.1080/1350485042000221526

Minutolo, M. C. 2003. Use of analytic hierarchy process modeling in the military decision making process for course of action evaluation and unit cohesion, in The 7th International Symposium on the Analytic Hierarchy Process (ISAHP 2003), 7-9 August 2003, Bali, Indonesia, 349-358. Available from Internet: http://www.isahp.org/2003Proceedings/paper/p39.pdf

Mukhametzyanov, I.; Pamučar, D. 2018. A sensitivity analysis in MCDM problems: a statistical approach, Decision Making: Applications in Management and Engineering 1(2): 51-80.

Nunić, Z. 2018. Evaluation and selection of manufacturer PVC carpentry using FUCOM-MABAC model, Operational Research in Engineering Sciences: Theory and Applications 1(1): 13-28.

Olivková, I. 2017. Methodology for assessment of electronic payment systems in transport using AHP method, Lecture Notes in Networks and Systems 36: 290-299.

https://doi.org/10.1007/978-3-319-74454-4_28

Pamučar, D.; Badi, I.; Korica, S., Obradović, R. 2018a. A novel approach for the selection of power-generation technology using a linguistic neutrosophic CODAS method: a case study in Libya, Energies 11(9): 2489.

https://doi.org/10.3390/en11092489

Pamučar, D.; Lukovac, V.; Božanić, D.; Komazec, N. 2018b. Multicriteria FUCOM-MAIRCA model for the evaluation of level crossings: case study in the Republic of Serbia, Operational Research in Engineering Sciences: Theory and Applications 1(1): 108-129.

Pamučar, D.; Stević, Ž.; Sremac, S. 2018c. A new model for determining weight coefficients of criteria in MCDM models: full consistency method (FUCOM), Symmetry 10(9): 393.

https://doi.org/10.3390/sym10090393

Pamučar, D.; Stević, Ž.; Zavadskas, E. K. 2018d. Integration of interval rough AHP and interval rough MABAC methods for evaluating university web pages, Applied Soft Computing 67: 141-163. https://doi.org/10.1016/j.asoc.2018.02.057

Popović, M.; Kuzmanović, M.; Savić, G. 2018. A comparative empirical study of analytic hierarchy process and conjoint analysis: literature review, Decision Making: Applications in Management and Engineering 1(2): 153-163.

Ramanathan, R. 2006. Data envelopment analysis for weight derivation and aggregation in the analytic hierarchy process, Computers \& Operations Research 33(5): 1289-1307. https://doi.org/10.1016/j.cor.2004.09.020

Raymundo, H.; Reis, J. G. M. 2017. Passenger transport drawbacks: an analysis of its "disutilities" applying the AHP approach in a case study in Tokyo, Japan, IFIP Advances in Information and Communication Technology 513: 545-552. https://doi.org/10.1007/978-3-319-66923-6_64

Rezaei, J. 2015. Best-worst multi-criteria decision-making method, Omega 53: 49-57. https://doi.org/10.1016/j.omega.2014.11.009

Saaty, T. L. 1980. The Analytic Hierarchy Process: Planning, Priority Setting, Resource Allocation. McGraw-Hill. 287 p.

Stefanović-Marinović, J.; Troha, S.; Milovančević, M. 2017. An application of multicriteria optimization to the two-carrier two-speed planetary gear trains, Facta Universitatis, Series: Mechanical Engineering 15(1): 85-95. https://doi.org/10.22190/FUME160307002S

Steuer, R. E.; Na, P. 2003. Multiple criteria decision making combined with finance: a categorized bibliographic study, European Journal of Operational Research 150(3): 496-515. https://doi.org/10.1016/S0377-2217(02)00774-9

Stević, Ž.; Pamučar, D.; Vasiljević, M.; Stojić, G.; Korica, S. 2017. Novel integrated multi-criteria model for supplier selection: case study construction company, Symmetry 9(11): 279. https://doi.org/10.3390/sym9110279

Stojić, G.; Stević, Ž.; Antuchevičienè, J.; Pamučar, D.; Vasiljević, M. 2018. A novel rough WASPAS approach for supplier selection in a company manufacturing PVC carpentry products, Information 9(5): 121. https://doi.org/10.3390/info9050121

Vaidya, O. S.; Kumar, S. 2006. Analytic hierarchy process: an overview of applications, European Journal of Operational Research 169(1): 1-29. https://doi.org/10.1016/j.ejor.2004.04.028

Wang, Y.-M.; Liu, J.; Elhag, T. M. S. 2008. An integrated AHPDEA methodology for bridge risk assessment, Computers \& Industrial Engineering 54(3): 513-525. https://doi.org/10.1016/j.cie.2007.09.002

Yang, Z. 2006. A two-stage DEA model to evaluate the overall performance of Canadian life and health insurance companies, Mathematical and Computer Modelling 43(7-8): 910919. https://doi.org/10.1016/j.mcm.2005.12.011

Zavras, A. I.; Tsakos, G.; Economou, C.; Kyriopoulos. J. 2002. Using DEA to evaluate efficiency and formulate policy within a Greek national primary health care network, Journal of Medical Systems 26(4): 285-292. https://doi.org/10.1023/A:1015860318972

Zinaja, D.; Arsić, M. 2011. Saobraćajna služba u obezbeđenju pokretljivosti vojske Srbije, Vojno delo (3): 258-283. (in Serbian). 